\title{
DEPURACIÓN Y REUTILIZACIÓN DE AGUAS RESIDUALES REGENERADAS EN LAS REGIONES DE MURCIA Y VALENCIA ${ }^{1}$
}

\author{
Antonio M. Rico Amorós, Ana Arahuetes Hidalgo y \\ Álvaro Francisco Morote Seguido \\ Instituto Interuniversitario de Geografía \\ Universidad de Alicante
}

\section{RESUMEN}

La reutilización de aguas depuradas constituye una fuente alternativa y sostenible para atender demandas agrarias, urbanas y de ocio. Además, su empleo permite liberar los recursos de agua de mayor calidad para garantizar usos prioritarios, como el urbanoturístico. En regiones con elevada vulnerabilidad frente a las sequías y con problemas de escasez hídrica, como son Murcia y Valencia, la reutilización de aguas regeneradas se ha afianzado durante las dos últimas décadas para garantizar suministros agrícolas, urbanos (jardines y baldeo de calles), recreativos (campos de golf) e industriales. Ello se ha visto favorecido por una mejora de las tecnologías de depuración, mediante tratamientos terciarios avanzados que incluyen desalinización. Este trabajo ofrece un balance de las iniciativas más destacadas de reutilización de aguas depuradas en las regiones de Murcia y Valencia, algunas de ellas pioneras a escala internacional.

Palabras clave: Depuración, reutilización, agua, Comunidad Valenciana, Murcia.

1. Esta investigación es resultado de la concesión de dos becas pre-doctorales. La primera de ellas, de Formación de Profesorado Universitario del Programa Nacional de Investigación Científica, Desarrollo e Innovación Tecnológica (FPU) y la segunda, del Ministerio de Economía y Competitividad. Además, se inserta en el Proyecto de Investigación "Urbanización y metabolismo hídrico en el litoral de Alicante: análisis de tendencias para el periodo 2000-2010" (CSO2012-36997-CO2-02) financiado por el Ministerio de Economía y Competitividad. 


\section{ABSTRACT}

Treatment and reuse of reclaimed water in the regions of Murcia and Valencia

The reuse of treated wastewater is an alternative and sustainable source to attend agricultural, urban and leisure demands. In addition, their use frees better quality water resources to ensure priority uses, such as urban tourism. In regions with high vulnerability to droughts and water scarcity problems, such as Murcia and Valencia, reuse of reclaimed water has been strengthened over the past two decades to ensure agricultural, urban (gardens and street cleaning), recreational (golf courses) and industrial supplies. This has been favored by an improvement in purification technology, using advanced tertiary treatment that include desalination. This paper offers an overview of the most important initiatives for the reuse of treated water in the regions of Murcia and Valencias, pioneers internationally.

Keywords: purification, reuse, water, Valencia, Murcia.

\section{INTRODUCCIÓN}

El agua, considerada ancestralmente como un recurso natural al servicio de las distintas sociedades humanas, ha adquirido, a partir de la segunda mitad del siglo $\mathrm{xx}$, carácter de bien escaso y de valor limitante en las regiones más vulnerables a las sequías (Rico et al., 1998). En la fachada mediterránea española, el agua se ha convertido en un recurso de vital importancia para el desarrollo socioeconómico, especialmente para el sector turístico y la agricultura (Hernández, 2013). Ante la escasez de recursos hídricos, los llamados recursos de agua no convencionales, principalmente reutilización de aguas regeneradas y desalinización, se han convertido en una fuente alternativa para paliar la insuficiencia hídrica en España. El notable desarrollo que han experimentado estas fuentes no convencionales desde finales del siglo xx se debe en parte al cumplimiento de la Directiva Comunitaria 91/271/CEE de depuración de aguas residuales urbanas que ha resultado decisiva para el impulso de la depuración en España, cuyas competencias están transferidas a las Comunidades Autónomas y que además, obliga a tratar las aguas residuales antes de ser vertidas o reutilizadas. Esta Directiva Europea define tres diferentes tipos de aguas residuales. En primer lugar, las aguas residuales urbanas, que son las generadas por el metabolismo humano en las viviendas y las actividades generadas en zonas comerciales y de servicios. En segundo lugar, las aguas residuales industriales, entendidas como todas las vertidas desde locales utilizados para cualquier actividad comercial o industrial que no sean domésticas ni de escorrentía pluvial. Y en tercer lugar, las aguas residuales urbanas originadas por la mezcla de aguas residuales consumidas en viviendas, en zonas industriales y con aguas pluviales. 
La reutilización de aguas residuales depuradas, aunque cuenta con actuaciones significativas (agricultura y usos recreativos), sigue siendo una asignatura pendiente de la planificación del agua en nuestro país, con la excepción que representan regiones como Murcia y Valencia, donde se ha recurrido al uso de estos recursos alternativos para usos agrícolas (Olcina y Moltó, 2010). Sin embargo, en algunas regiones españolas la gran expansión del poblamiento urbano-turístico experimentado desde mediados de la década de 1990 hasta el estallido de la crisis inmobiliaria y financiera de 2007/08, con cambios cuantitativos y cualitativos en los modelos residenciales (urbanismo disperso con nuevos equipamientos como jardines, piscinas, campos de golf, etc.), podría haber representado un aliciente para incrementar el consumo de estos recursos alternativos en usos no agrícolas (March et al., 2013).

En relación con el cambio climático, la adaptación a éste, constituye uno de los mayores retos de las sociedades a escala global (IPCC, 2014). En España, los efectos previstos del calentamiento térmico planetario en las condiciones climáticas se manifestarían, según los modelos predictivos, en una disminución del volumen de precipitaciones y un incremento en su variabilidad temporal y espacial (AEMET, 2015). Algunas regiones, como las ribereñas del Mediterráneo van a resultar especialmente sensibles a los efectos de estos cambios en los patrones de precipitación (ESPON-Climate, 2013), debido tanto a la escasez de lluvias como a la necesidad de atender unas demandas de agua que se incrementaron de forma notable en las dos últimas décadas del siglo xx, si bien, los consumos, al menos los urbanos, se han moderado e incluso reducido desde mediados de la pasada década (ver Gil et al., 2015).

Hasta la sequía ibérica sufrida entre 1992-95, la solución a los problemas de carencia de recursos hídricos en España, planteada en anteriores períodos de escasez de precipitaciones, se basó en la posibilidad de obtener y poner a disposición de los diferentes usos de nuevos volúmenes de agua que garantizan éstos, generalmente de origen subterráneo (Morales, 2001). Por ello, se primaban actuaciones y políticas dirigidas a generar más oferta de recursos sin tomar medidas racionales en el control de las demandas (Rico et al., 1998). Dicho periodo de escasez de precipitaciones abrió el debate de la necesidad de aprovechamiento y la ordenación integrada de la totalidad de recursos potencialmente útiles, centrando la atención en las denominadas fuentes no convencionales, que engloban las aguas residuales depuradas y la desalinización de aguas salobres o marinas.

De todas las actuaciones que se podrían acometer para aumentar la disponibilidad de recursos, es la relativa a la depuración y reutilización de aguas residuales en agricultura, usos urbanos (baldeo de calles, riego de parques y jardines) y otros usos (campos de golf, medianas de carreteras y autopistas) la que más posibilidades concede a corto plazo (Rico, 1996). Un rasgo característico de estos recursos es que su disponibilidad puede permanecer, al menos 
parcialmente, ajena a las variaciones que sufren las distintas fases del ciclo hidrológico en la naturaleza. Desde el último cuarto de siglo de la pasada centuria, se ha propuesto repetidamente la tesis de que el tratamiento avanzado de las aguas residuales municipales e industriales proporciona unos recursos de tanta calidad que no deberían desperdiciarse, sino destinarse a fines provechosos (Asano, 1997). Además, el tratamiento y la reutilización de estos recursos sobresalen en cuanto a sus ventajas económicas y ecológicas frente a la desalinización de agua marina y, a pesar de la reducción de los costes de esta última tecnología, la diferencia entre las dos soluciones aún se mantiene gracias a los progresos simultáneos del reciclaje (Angelakis et al., 1999).

En España, la normativa específica que regula el empleo de estos recursos se recoge en el Real Decreto 1620/2007, mediante el cual se establece el régimen jurídico de la reutilización de las aguas depuradas. En este sentido, este real decreto define estos recursos como «aguas residuales depuradas que, en su caso, han sido sometidas a un proceso de tratamiento adicional o complementario que permite adecuar su calidad al uso al que se destinan». Al proceso de tratamiento necesario para que un agua residual pueda reutilizarse se le denomina «regeneración», y consiste en devolverle, parcial o totalmente, el nivel de calidad que tenía antes de ser consumida, recuperando así cualidades que la hacen útil para atender determinados usos consuntivos. Las calidades del agua regenerada contempladas en el Anexo I.A del RD de reutilización son un total de 14, agrupadas en cinco tipos de usos: urbanos, agrícolas, industriales, recreativos y ambientales. Las aguas residuales tras pasar por los procesos de tratamiento primario y secundario, pueden ser sometidas a un proceso terciario, y en ocasiones a uno avanzado, para adecuar la calidad de las aguas al destino deseado, incluyendo la desalinización.

También, no cabe olvidar la importancia que tiene el canon de saneamiento. Éste, se trata de un impuesto propio que grava la producción de aguas residuales generadas por el metabolismo humano, la actividad doméstica, pecuaria, comercial o industrial, que realicen su vertido final a una red de saneamiento municipal. Las diferentes entidades que gestionan el saneamiento de aguas, que en el caso del área de estudio de esta investigación, (EPSAR) en la Comunidad Valenciana, y en la Región de Murcia (ESAMUR), consideran este canon como un «impuesto ecológico» cuyo fin es mejorar el nivel de conservación del medio. Su tarifación depende de los usos: en el caso del doméstico se divide en tramos de población a los que corresponde una cuota de consumo y otra cuota de servicio; y en el caso del uso industrial existe una cuota de servicio y otra de servicio que varía en función del calibre del contador.

La literatura científica relacionada con las aguas residuales apunta hacia un claro cambio de paradigma, puesto que de ser consideradas bajo la óptica del riesgo ambiental (inundaciones, contaminación, etc.), han pasado de manera 
progresiva a ser tratadas bajo la óptica de flujos que se pueden valorizar (Sedlak, 2014). En el caso de las aguas residuales urbanas, la mejora tecnológica en los sistemas de depuración, especialmente a partir de los tratamientos terciarios avanzados, que combinan ultrafiltración y desalinización, ha favorecido en un aumento de los usos potenciales del agua regenerada. Desde hace dos décadas, las aguas regeneradas se utilizan para el regadío y para funciones ambientales en ámbitos como la Costa Brava en Gerona o áreas de la Comunidad Valenciana y la Región de Murcia (Gil y Rico, 2015). Sin embargo, su uso es menos frecuente en ámbitos urbanos si bien destacan algunas iniciativas municipales vinculadas con procesos de planificación territorial sostenible (Agendas 21 locales, Redes de municipios sostenibles, etc.). Al igual que en el caso de las aguas pluviales tampoco se dispone de información sistematizada sobre iniciativas a nivel local en el uso de estos flujos. Por tanto, un mejor conocimiento acerca de las características de estos recursos no convencionales, de sus usos, sistemas de gestión y de su potencial representaría un claro avance hacia un modelo de planificación más sostenible y resiliente ante los posibles efectos del cambio climático en España.

En otros casos, la movilización de estos recursos a nivel municipal vendría influida por la adopción de programas de mejora ambiental mediante Agendas 21 locales, planes municipales de turismo, ayudas de fondos estructurales europeos, etc. Y, quizá más a menudo, la movilización de estos recursos obedecería a periodos cada vez más frecuentes de estrés hídrico en forma de sequías. Finalmente, la generación de nuevos flujos puede deberse a acciones no estrictamente pensadas para tal finalidad sino para otros cometidos. Así ocurre con los tanques de anticontaminación de playas y con otras estructuras de contención de aguas pluviales para evitar inundaciones producidas por precipitaciones de gran intensidad. Examinar y sistematizar todas estas casuísticas contribuiría a comprender mejor los distintos factores que intervienen en la valorización de recursos hídricos no convencionales.

\section{LA REUTILIZACIÓN DE AGUAS DEPURADAS. EVOLUCIÓN Y ESTADO ACTUAL}

\section{Las aguas regeneradas en el ámbito internacional}

En los países desarrollados y en desarrollo, la rápida urbanización y la consiguiente creciente demanda de agua potable, para uso industrial y/o agrícola, supone un serio inconveniente para aquellos países caracterizados por la insuficiencia hídrica. Estas circunstancias constituyen un serio problema en la Región del Mediterráneo y, sobre todo, en las zonas áridas y semiáridas de la Península Ibérica, Oriente Medio y norte de África. La reutilización en estas zonas para el regadío es una estrategia adecuada y acertada, ya que en estos territorios se encuentra el $60 \%$ de la población mundial con recursos naturales renovables 
de menos de $1.000 \mathrm{~m}^{3} /$ habitante/año (Kamizoulis et al., 2003). También cabe destacar los altos volúmenes de aguas regeneradas en la zona sur de la Costa Oeste de los Estados Unidos y México. En valor absoluto México, China y Estados Unidos son los países con mayor volumen de reutilización de aguas residuales, pero en los dos primeros se contabilizan las residuales no tratadas. Así, México reutiliza el 31\% de las aguas residuales (1.290 hm³/año); y EE.UU. el 30\% (1.264 $\left.\mathrm{hm}^{3} / \mathrm{año}\right)$, destacando los estados de Florida con el 28\% de reutilización, California (22\%), Arizona (21\%), Texas (10\%) y Maryland (7\%) (CNA, 2002; USGS, 1995).

En 1990, en California, las aguas residuales generadas en los distintos municipios, se elevaba a $4.125 \mathrm{hm}^{3} /$ año, de los que se reutilizaban, tras su depuración, $300 \mathrm{hm}^{3}$ (el 7,27\%) (Rico et al., 1998). Los sistemas de reutilización han ocupado un lugar reseñable en los Estados Unidos desde el año 1962, según estima la Academia Nacional de Ciencias, principalmente en California, Virginia, Texas, Georgia, Arizona y Colorado con numerosas iniciativas de reutilización de agua regenerada para garantizar los suministros municipales. El condado de Orange en California, por ejemplo, produce unos $260.000 \mathrm{~m}^{3} /$ día de agua regenerada que es inyectada en acuíferos mediante estanques de infiltración (RWL Water, 2013).

El análisis de la reutilización de residuales a escala internacional también puede abordarse considerando los caudales utilizados por habitante, donde Qatar, Israel y Kuwait son los países que más cantidad de estos recursos reutilizan per cápita. En cambio, si se considera lo que representan las residuales en el conjunto global de todos los recursos hídricos movilizados son Kuwait, Qatar, Jordania e Israel los países donde esta fuente de suministro adquiere mayor relevancia, con el $28,9 \%, 21,2 \%, 19,5 \%$ y $9,6 \%$ respectivamente (RWL Water, 2013).

El uso más extendido de las aguas depuradas es el riego agrícola, aunque de forma creciente se utilizan también para atender demandas urbanas (parques, jardines, baldeo de calles), industriales y recreativas. Como casos muy singulares, el agua residual se pude regenerar para el consumo humano en misiones espaciales, en la Estación Concordia en el Ártico o en algunas misiones militares. Tan sólo existen dos países que actualmente están produciendo agua potable a partir de residuales a gran escala como son Namibia y Singapur. Por ejemplo, en Namibia, la primera de estas iniciativas tuvo lugar en 1968, como resultado de una fuerte sequía, que propició la construcción de una depuradora de 4.800 $\mathrm{m}^{3} /$ día, destinada a la producción de agua potable, constituyendo ésta una fuente de suministro viable y menos costosa que otras alternativas convencionales.

En Europa la reutilización de residuales no está muy extendida, con la excepción de algunas regiones de España o Italia con problemas de escasez de agua. Es práctica habitual que las aguas depuradas se viertan a ríos, lagos y al medio marino, aunque desde la Unión Europea se intenta promover proyectos para potenciar la reutilización, si bien ello tropieza con varios inconvenientes 
como la ausencia de normas sanitarias comunes en la UE sobre su empleo; en muchos casos, prohibición expresa de comercialización de productos agrícolas irrigados con agua regenerada; costes de producción y tarifas de suministro elevadas, por un recurso que no siempre tiene las condiciones de calidad necesarias; poca sensibilización de la administración y los usuarios sobre las ventajas e inconvenientes de la reutilización de residuales; ausencia de infraestructuras adecuadas de captación, distribución y manejo de estos recursos no convencionales. Por lo tanto sólo en zonas vulnerables a la sequía y de alto déficit hídrico como padecen algunas regiones de España e Italia, se ha difundido el empleo de residuales depuradas.

Figura 1. Estrés hídrico y volúmenes de agua reutilizada en Europa

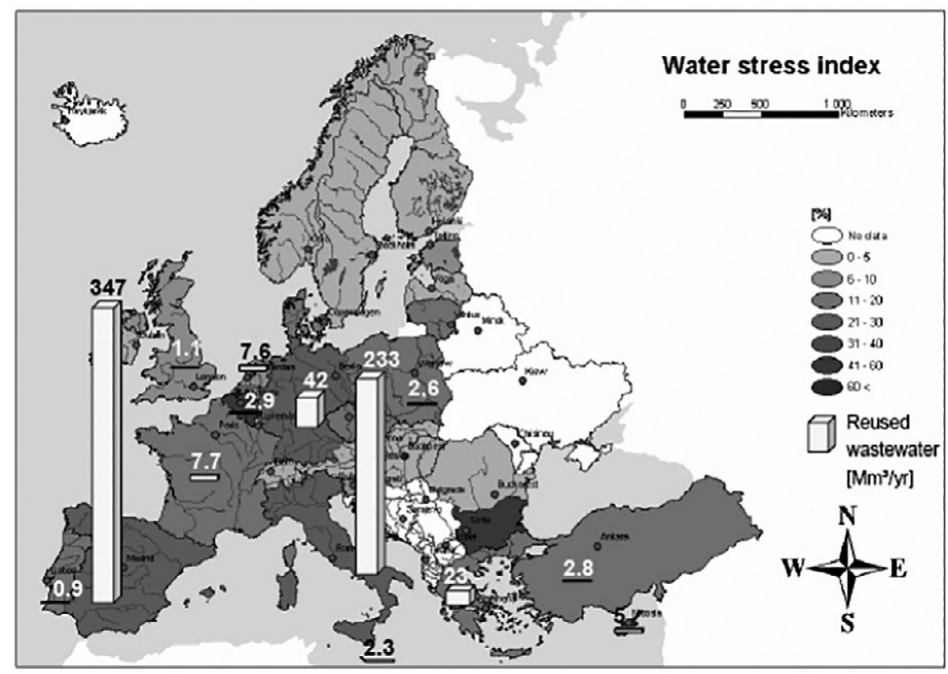

Fuente: AQUAREC (2006).

En el contexto europeo, es en las regiones del sur y de la ribera mediterránea donde más podría afianzarse la reutilización de residuales, particularmente en España que todavía tiene un elevado potencial de crecimiento. No obstante, desde 1985 hasta 2007 las iniciativas de utilización de aguas depuradas han sido desarrolladas sobre todo por comunidades de regantes bajo los requisitos de contar con una concesión de uso, y con un informe de la autoridad sanitaria. La exhaustiva regulación que introduce el R.D. 1620/2007, en materia de calidad sanitaria del agua regenerada para cada tipo de uso, puede condicionar la extensión de la reutilización a usos agrícolas muy sensibles como el riego de hortalizas. El Proyecto AQUAREC preveía que España incrementaría los $300 \mathrm{hm}^{3}$ reutilizados en 2006 a 1.200 en 2015, lo que representaba más de la mitad de los 
$2.000 \mathrm{hm}^{3}$ que se proyectaban para los diez países seleccionados. En Israel, que partía de $280 \mathrm{hm}^{3} /$ año, se pretendía llegar a 380 y en Italia de 45 a 250 . El resto de países quedaban muy por debajo en la realidad y en las expectativas (Olcina y Moltó, 2010).

Tabla 1. Usos potenciales del agua residual regenerada

\begin{tabular}{|c|c|}
\hline Reutilización & Usos principales del agua \\
\hline Urbana & $\begin{array}{l}\text { - Riego de parques públicos, estadios } \\
\text { deportivos, jardines de escuelas, áreas } \\
\text { verdes de edificios públicos, industrias, } \\
\text { centros comerciales y de carreteras y } \\
\text { autopistas } \\
\text { - Riego de áreas ajardinadas de las } \\
\text { residencias unifamiliares y multifamiliares } \\
\text { - Lavado de vehículos, ventanas, agua } \\
\text { de mezcla para fertilizantes líquidos, } \\
\text { herbicidas y pesticidas } \\
\text { - Usos ornamentales: fuentes, estanques } \\
\text { - Limpieza de calles } \\
\text { - Protección contra el fuego } \\
\text { - Agua de cisterna para urinarios públicos }\end{array}$ \\
\hline Industrial & $\begin{array}{l}\text { - Refrigeración } \\
\text { - Procesos industriales }\end{array}$ \\
\hline \multicolumn{2}{|l|}{ Riego agrícola } \\
\hline \multicolumn{2}{|l|}{ Riego campos de golf } \\
\hline \multicolumn{2}{|c|}{ Restauración de hábitats naturales y mejora del entorno } \\
\hline \multicolumn{2}{|l|}{ Usos recreativos } \\
\hline \multicolumn{2}{|c|}{ Recarga de acuíferos (control intrusión marina) } \\
\hline Aumento de recursos & $\begin{array}{l}\text { - Reutilización indirecta (descarga de } \\
\text { acuíferos y descarga de embalses, ríos y } \\
\text { lagos) }\end{array}$ \\
\hline
\end{tabular}

Fuente: Environment Policy Agency (1992).

\section{Las aguas regeneradas en España}

La reutilización directa del agua depurada es una práctica cada vez más empleada internacionalmente y muy extendida en algunas regiones españolas que sufren un balance hídrico deficitario, agravado durante situaciones de sequía (Morales et al., 2000). En estas regiones la reutilización permitiría incrementar la disponibilidad del recurso, más aún en las zonas costeras donde el agua depurada es vertida al mar. En este caso el recurso regenerado puede garantizar usos agrícolas, reduciendo el consumo de agua subterránea o superficial de mayor calidad que puede destinarse a suministro urbano. Desde el punto de vista de la 
gestión, el uso de agua regenerada ha sido promovido por los diferentes estamentos públicos, mediante ordenanzas municipales, como es el caso de Madrid o Lanzarote, planes autonómicos o el Plan Nacional de Reutilización de Aguas impulsado por el Ministerio de Agricultura, Alimentación y Medio Ambiente con el cual se pretendía alcanzar un volumen de reutilización de $1.130 \mathrm{hm}^{3}$ en el ciclo de planificación que ha concluido en 2015. España es uno de los países más avanzados del mundo en esta materia, y este logro fue reconocido en 2014 por la Unión Europea en sus premios Emas, con los cuales galardona a los mejores proyectos de gestión ambiental. En este año recibió 6 distinciones, entre las que destacó la concedida al Aeropuerto de Menorca por haber reducido su consumo de agua mediante la reutilización de residuales.

En relación con el volumen de agua depurada, es complejo conocer con exactitud datos siquiera aproximados de producción y de reutilización. Los informes que elaboran los distintos organismos estatales y autonómicos con competencias en esta materia, no siempre ofrecen resultados coincidentes. En la década de los noventa, según estimaron Rico et al., (1998), el volumen de agua reutilizada en España no alcanzaba la cifra de $200 \mathrm{hm}^{3} /$ año, lo que suponía alrededor del $8 \%$ del total de residuales depuradas. En 1995, 28 capitales de provincia no tenían depuradora o contaban con instalaciones no conformes a los requisitos exigidos por la Directiva Comunitaria 91/271. Según analizaron Olcina y Rico (1999), en 1995, estimaron que el volumen que se reutilizaba en España no excedería de $150 \mathrm{hm}^{3} / \mathrm{año}$, lo que supone un $6 \%$ del volumen de aguas negras depuradas. En ese mismo año, en España existían más de 3.226 depuradoras en servicio que estaban capacitadas para atender la carga contaminante teórica generada por un $60 \%$ de la población de derecho. El tipo de tratamiento mayoritario era el primario con 2.065 EDAR en servicio, 1.135 secundario y tan sólo 26 con tratamiento terciario (el 2,29\%) (Martínez, 1995).

En 1998, según el Instituto Nacional de Estadística, el caudal tratado en toda España era de $1.022 \mathrm{hm}^{3}$, mientras que el volumen reutilizado $186 \mathrm{hm}^{3}$ (el 18,26\%). En el 2000, el volumen de aguas depuradas ascendía $4.667 \mathrm{hm}^{3}$, mientras que las reutilizadas sumaban $230 \mathrm{hm}^{3}$ (el 4,9\%). Posteriormente, en el año 2002, el volumen reutilizado ascendía a $346 \mathrm{hm}^{3} /$ año, destinándose para usos agrícolas la mayoría con $261 \mathrm{hm}^{3}(75 \%)$, ambientales $65 \mathrm{hm}^{3}(18 \%)$, recreativos $26 \mathrm{hm}^{3}(7 \%)$, usos urbanos $1 \mathrm{hm}^{3}(028 \%)$ e industriales $1 \mathrm{hm}^{3}(0,28 \%)$. Según el estudio de Olcina (2002), en ese mismo año, en España, el volumen de agua depurada era de $2.500 \mathrm{hm}^{3}$, mientras que las reutilizadas $230 \mathrm{hm} /$ año $(9 \%)$ y además, de ese volumen depurado, el $61 \%$ contaba con tratamiento de regeneración.

Según el «Informe sobre la situación de la reutilización de efluentes depurados en España», el volumen de agua reutilizada en España en 2006 alcanzó $\operatorname{los} 368 \mathrm{hm}$ 3/año. Además, dicho informe señalaba ciertos aspectos que deberían 
mejorar en España para elevar la eficiencia de la reutilización. Se identificaban deficiencias en la gestión, explotación y control de los sistemas de depuración; existencia de vertidos incontrolados en las redes de saneamiento que dificultaban la depuración de las aguas residuales y su regeneración hasta los estándares de calidad previstos en la legislación; necesidad de invertir en los sistemas de reutilización para que cumplieran las obligaciones previstas en el real decreto de reutilización; y necesidad de adaptar el régimen concesional a los usos existentes de aguas regeneradas.

En 2007, según estimaciones recogidas en el Plan Nacional de Calidad de las Aguas, existían en España más de 2.500 EDAR que depuraban más de $3.375 \mathrm{hm}^{3} /$ año, y se reutilizaban tan sólo unos $450 \mathrm{hm}^{3} /$ año, que suponían poco más del 13\% del total. Ello mostraba el elevado potencial de esta fuente para la generación de nuevos recursos hídricos, en un escenario futuro donde las perspectivas del cambio climático apuntan a una disponibilidad decreciente de recursos hídricos naturales. Según la distribución por usos del agua depurada, se situaba en unas tres cuartas partes para uso agrícola, del orden del $12 \%$ para usos recreativos y campos de golf, el 6\% para servicios urbanos, el 4\% para usos ecológicos y recarga de acuíferos, y en torno al 3\% para uso industrial (MMA, 2007).

En la década del 2000, también cabe citar la incidencia que ha tenido el Programa AGUA, ya que uno de los objetivos fundamentales era incorporar en la mayor medida posible, la reutilización de aguas depuradas para incrementar las disponibilidades de recursos hídricos (Rico, 2010). En 2010, según datos del Ministerio de Medio Ambiente, Rural y Marino, reflejados en el Plan Nacional de Calidad de las Aguas, el volumen depurado superaba $\operatorname{los} 3.300 \mathrm{hm}^{3}$ y existían más de 2.533 EDAR donde destacaban por su número, Andalucía con 545 depuradoras (el 21,5\%), Cataluña con 281 (el 11,1\%) y Comunidad Valenciana con 270 (el 10,6\%). Según estimaciones de Olcina y Moltó (2010), en dicho año, los recursos no convencionales podrían aportar teóricamente más de 4.500 $\mathrm{hm}^{3} / \mathrm{año}$, si bien, su uso efectivo se reducía a $450 \mathrm{hm}^{3}$; la capacidad de la desalinización se acercaría a $700 \mathrm{hm} /$ año. Según el Instituto Nacional de Estadística, en 2012, el volumen de aguas depuradas ascendía a $4.941 \mathrm{hm}^{3}$, reutilizándose $450 \mathrm{hm}^{3}(9 \%)$. Estos datos están alejados de las previsiones que se barajaron en el Congreso Mundial de Desalinización, organizado por la International Desalination Association (IDA) en Gran Canaria en 2007, que indicaban que España triplicaría la capacidad de reutilización en 2015 hasta alcanzar los 1.200 $\mathrm{hm}^{3} /$ año (Iagua, 2007).

Si se analiza el estado de las aguas depuradas y reutilizadas por Comunidades Autónomas, una de las conclusiones relevantes que se extrae es que las zonas que sufren una mayor insuficiencia hídrica, son las más avanzadas en este ámbito. Salvo en Murcia, Baleares, Comunidad Valenciana y Canarias, en el 
Tabla 2. Depuración y reutilización de aguas residuales en España $\left(\mathrm{hm}^{3}\right)$

\begin{tabular}{|c|c|c|c|}
\hline & Volumen depurado & Volumen reutilizado & $\begin{array}{l}\% \text { de agua } \\
\text { reutilizada }\end{array}$ \\
\hline Andalucía & 850,76 & 87,74 & 10,31 \\
\hline Aragón & 187,21 & 1,24 & 0,66 \\
\hline Asturias & 149,50 & 0,09 & 0,06 \\
\hline Baleares & 144,09 & 43,02 & 29,86 \\
\hline Canarias & 134,06 & 31,15 & 23,24 \\
\hline Cantabria & 93,94 & 3,80 & 4,05 \\
\hline Castilla y León & 431,02 & 3,08 & 0,71 \\
\hline Castilla-La Mancha & 221,26 & 1,48 & 0,67 \\
\hline Cataluña & 648,40 & 28,50 & 4,39 \\
\hline Com.Valenciana & 450,16 & 270,00 & 59,98 \\
\hline Extremadura & 164,21 & 0,00 & 0 \\
\hline Galicia & 348,83 & 0,94 & 0,27 \\
\hline Madrid & 573,41 & 11,37 & 1,98 \\
\hline Murcia & 109,00 & 62,54 & 57,37 \\
\hline Navarra & 70,31 & 0,00 & 0 \\
\hline País Vasco & 322,57 & 3,40 & 1,05 \\
\hline Rioja, La & 50,49 & 0,00 & 0 \\
\hline Ceuta y Melilla & 11,97 & 0,10 & 0,82 \\
\hline España & $4.961,17$ & 548,45 & 11,05 \\
\hline
\end{tabular}

Fuente: Recogida y tratamiento de las aguas residuales por Comunidad Autónoma. Instituto Nacional de Estadística, 2012.

resto de España apenas se utiliza esta fuente no convencional. En 1995, los mayores volúmenes de depuración se encontraban en Cataluña y Madrid, ambas superando los $500 \mathrm{hm}^{3} /$ año, seguido por la Comunidad Valenciana con $300 \mathrm{hm}^{3} /$ año, Murcia con $67 \mathrm{hm}^{3} /$ año, Baleares con $66 \mathrm{hm}^{3} /$ año y Canarias con $56 \mathrm{hm}^{3} /$ año. Sin embargo, en el año 2000, Cataluña reutilizaba el $3 \%\left(16,4 \mathrm{hm}^{3} /\right.$ año),

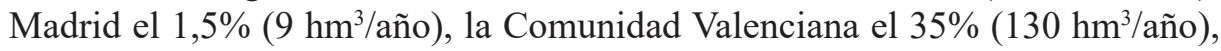
Murcia el 100\% (60 hm²/año), Canarias el 36\% (20 hm³/año), y Baleares el 37\% (25 hm³/año) (Olcina, 2002). En 2012, según el INE, la Comunidad Valenciana y la Región de Murcia regeneran y reutilizaban más del 50\% del volumen depurado (ver Tabla 2). En contraste, en aquellas regiones con mayor disponibilidad de recursos hídricos como Cantabria, Navarra o la Rioja, el porcentaje de reutilización es cero. En España, la media se sitúa en el 11,05\%. 
LA GESTIÓN Y APROVECHAMIENTO DE LAS AGUAS DEPURADAS EN LA REGIÓN DE Murcia

Producción de aguas depuradas y su reutilización en la Región de Murcia. Evolución y estado actual

La Demarcación Hidrográfica del Segura (DHS) es una de las cuencas mediterráneas que más sufren la escasez de agua, con demandas muy superiores a los recursos disponibles (Morales et al., 2005). Esta situación podría agravarse con la probable disminución de recursos en el medio y largo plazo, bien, debido a una disminución de los registros pluviométricos asociada al cambio climático o simplemente, por un incremento de las demandas asociadas, principalmente, a la actividad agrícola (Pérez et al., 2014). El caso de la Región de Murcia resulta particularmente interesante ya que ha registrado uno de los crecimientos más rápidos en materia de reutilización en comparación con el resto de autonomías españolas. Los planes de saneamiento, las tecnologías de regeneración y las medidas de reutilización han permitido aprovechar más de $131 \mathrm{hm}^{3} /$ año en regadío y en usos ambientales (Pérez et al., 2014). La región ocupa una posición cimera en el panorama nacional tanto por el grado de cumplimiento de la Directiva Comunitaria 91/271 como por alcanzar la reutilización plena de todos los caudales depurados. Aunque el ámbito de la DHS exceda el de la región de Murcia, según datos del Ministerio de Agricultura, en la Demarcación del Segura se reutilizaría el 100\% del agua depurada, un dato coincidente con el ofrecido por Olcina y Moltó (2010).

La reutilización de aguas supone una fracción muy considerable de los recursos hídricos disponibles en la DHS, y según datos de la Confederación, a junio de 2009, se habían otorgado 154 concesiones con un volumen total de $107 \mathrm{hm}^{3} /$ año, que suponía el 69\% del volumen total depurado (157 hm³/año). La disponibilidad de infraestructuras y la existencia de normas legales que regulan su empleo, no despeja completamente algunos de los inconvenientes que suscita la reutilización. Entre ellos, los regantes denuncian la creciente salinidad de las aguas regeneradas y los episodios de contaminación industrial que se producen con cierta frecuencia. El incremento de conductividad podría deberse al vertido de aguas domésticas con mayores contenidos salinos, tal vez, por la proliferación de dispositivos de ablandamiento y desalinización domésticos, aunque también se advierte un aumento de la salinidad debido al achique de aguas freáticas salobres de los garajes.

La Entidad de Saneamiento y Depuración de la Región de Murcia (ESAMUR) es el órgano encargado del mantenimiento y explotación de las instalaciones públicas de tratamiento de las aguas residuales urbanas de esta Comunidad Autónoma. Este organismo se creó en 2002 tras la aprobación del Decreto 90/2002, de 20 de mayo, que aprobó sus Estatutos y funciones 
como Empresa Regional. Los recursos económicos que maneja proceden de la exacción del Canon de Saneamiento, que es un tributo ambiental finalista que recauda y administra la propia Entidad. En la Región de Murcia, el nuevo Sistema General de Gestión se plasmó en la Ley 3/2000, de 12 de julio, de Saneamiento y Depuración de Aguas Residuales e Implantación del Canon de Saneamiento. Este instrumento financiero ha permitido construir y explotar el conjunto de instalaciones de depuración que se proyectaron en el Plan General de Saneamiento y Depuración 2001-2010.

Tabla 3. Evolución de la tarifa del Canon de Saneamiento (2002-2014)

\begin{tabular}{|l|c|c|c|c|c|c|c|c|c|}
\hline \multicolumn{1}{|c|}{ Tipo de tarifa } & $\mathbf{2 0 0 2}$ & $\mathbf{2 0 0 4}$ & $\mathbf{2 0 0 6}$ & $\mathbf{2 0 0 8}$ & $\mathbf{2 0 1 1}$ & $\mathbf{2 0 1 2}$ & $\mathbf{2 0 1 3}$ & $\mathbf{2 0 1 4}$ & $\begin{array}{c}\text { Incremento } \\
\mathbf{\%} \mathbf{2 0 0 2 - 2 0 1 4}\end{array}$ \\
\hline $\begin{array}{l}\text { Tarifa doméstica } \\
\begin{array}{l}\text { Cuota fija }(€ / \text { abonado/año) } \\
\text { Cuota variable }\left(€ / \mathrm{m}^{3}\right)\end{array}\end{array}$ & $\begin{array}{c}24,00 \\
0,20\end{array}$ & $\begin{array}{c}25,70 \\
0,21\end{array}$ & $\begin{array}{c}26,70 \\
0,22\end{array}$ & $\begin{array}{c}27,90 \\
0,23\end{array}$ & $\begin{array}{c}30,00 \\
0,25\end{array}$ & $\begin{array}{c}32,00 \\
0,25\end{array}$ & $\begin{array}{c}33,00 \\
0,28\end{array}$ & $\begin{array}{c}34,00 \\
0,29\end{array}$ & $30 \%$ \\
\hline Tarifa industrial $\left(\boldsymbol{\epsilon} / \mathbf{m}^{3}\right)$ & 0,27 & 0,29 & 0,30 & 0,32 & 0,34 & 0,37 & 0,38 & 0,40 & $32 \%$ \\
\hline
\end{tabular}

Fuente: ESAMUR, 2014. Elaboración propia.

La recaudación del canon de saneamiento se lleva a cabo a través de las entidades suministradoras de agua, figurando su importe en los correspondientes recibos que presentan al cobro las concesionarias de los servicios municipales de agua potable. En el caso de establecimientos industriales, conectados a las redes de alcantarillado urbano, la tarifa aplicable es afectada por un coeficiente que depende de la contaminación aportada con el vertido. En la tabla 3 , se puede apreciar que tanto la tarifa doméstica como la industrial se han incrementado notablemente entre 2002-2014. En este sentido, la tarifa doméstica, que se desagrega entre cuota fija ( $€ /$ abonado/año) y cuota variable $\left(€ / \mathrm{m}^{3}\right)$, se han incrementado un 30 y $31 \%$ respectivamente. En relación con la tarifa industrial, ésta se ha incrementado de $0,27 € / \mathrm{m}^{3}$, en 2002 , a $0,40 €$ en 2014 .

En relación con las obras de mejora y rehabilitación, cabe indicar por su trascendencia, el Programa de Actuaciones de Rehabilitación y Mejora (P.A.R.M.), que permite dotar de instalaciones de depuración a pequeños núcleos urbanos, garantizando de esta manera la depuración de agua a la población rural. En este sentido, en los últimos años se han invertido alrededor de 600 millones de euros, en los que ha tenido una participación crucial la aportación de fondos europeos. Actualmente, la recogida y tratamiento adecuado de las aguas residuales generadas por la población y la industria conectada a redes de alcantarillado, se extiende a un total de 1.348.794 habitantes que equivale al 99,1\% de la población urbana y que quedan recogidos en 45 municipios. El resto de población urbana con obras de saneamiento en curso o pendientes de actuación 
corresponde a 108 Aglomeraciones Urbanas de pequeño tamaño, totalizando un conjunto de 12.704 habitantes. Finalmente, el censo de población recoge la existencia de 113.402 habitantes que corresponde a población rural o residencial aislada no conectada ni próxima a una red pública de saneamiento. Una buena parte de las aguas regeneradas en este tipo de viviendas llega sin embargo hasta las plantas de tratamiento a través de los servicios de vaciado y limpieza de fosas sépticas que descargan en las EDAR autorizadas para ello. Sumando esta población diseminada a la población urbana se alcanzaría una población censada en 2011 de 1.470 .069 habitantes.

En la Región de Murcia, el conjunto de instalaciones de depuración asciende a 88 Estaciones con tratamiento biológico, y 34 (38\%) de ellas cuentan además con Tratamiento Terciario de regeneración. Un elemento importante a tener en cuenta en la depuración de aguas residuales es el coste energético que puede suponer una tercera parte de los costes brutos de explotación. Esta circunstancia ha obligado a introducir una serie de medidas para el incremento de la eficiencia energética, a partir del Plan de Mejora Energética (2007), que ha apostado por un mayor aprovechamiento de biogás.

En la década de los noventa, en Murcia se sufrían serios problemas por la escasa eficiencia en el saneamiento y depuración, que se vinculaban entre otras causas, a la insuficiente capacidad de la red de alcantarillado, y este hecho se agravaba cuando se producían lluvias, al actuar también como colectores pluviales. Además, parte de esa red, como sucedía con las ciudades de Murcia y de las Vegas Medias y Baja, estaban conectadas con las viejas acequias de riego que surcaban el subsuelo de los núcleos urbanos (Rico et al., 1998). Diseños técnicos obsoletos no conformes a las exigencias comunitarias, emplazamientos poco adecuados con predominio de estaciones depuradoras de tipo primario (lagunaje), ciclos de vida limitados en ocasiones a la jornada de apertura, explotación y mantenimiento nulo a cargo de los ayuntamientos son algunos de los aspectos que expresan la compleja situación en la década de los noventa. Ejemplo de ello era que el río Segura se había convertido, a perjuicio de los usuarios, en un emisario al mar Mediterráneo de los vertidos urbanos e industriales sin depurar de las ciudades de la Vega Media y Baja. Desde los inicios de la gestión del saneamiento de agua por parte de ESAMUR, el volumen de agua depurada y eficiencia ha ido en aumento. En el año 2003 se depuraron 88 $\mathrm{hm}^{3}$ siendo el rendimiento del $84 \%$. A partir de esa fecha, dicho rendimiento ha aumentado considerablemente hasta alcanzar valores del $99 \%$ en 2008 , valor que se ha mantenido constante hasta la actualidad. El volumen máximo depurado se registró en 2011 con $118 \mathrm{hm}^{3}$, en cambio, este volumen ha descendido ligeramente hasta los $110 \mathrm{hm}^{3}$ del año 2013. Cabe indicar, que el mayor volumen depurado se concentra en las EDAR dimensionadas para tratar más de 100.000 habitantes equivalente (h-e) con el 50,22\% (Tabla 4). 
Tabla 4. Volumen de agua tratada en las EDAR de la Región de Murcia, 2013

\begin{tabular}{|l|c|c|c|}
\hline $\begin{array}{c}\text { Tamaño EDAR } \\
\text { Habitantes equivalentes }\end{array}$ & $\begin{array}{c}\text { Número } \\
\text { EDAR }\end{array}$ & $\begin{array}{c}\text { Caudal tratado } \\
\mathbf{m}^{\mathbf{3} / \mathbf{a n ̃ o}}\end{array}$ & $\mathbf{\%}$ \\
\hline$<499$ & 26 & 581.537 & 0,52 \\
\hline $500-1.199$ & 17 & 913.480 & 0,82 \\
\hline $2.000-19.999$ & 23 & 20.470 .286 & 18,47 \\
\hline $20.000-100.000$ & 19 & 33.203 .531 & 29,96 \\
\hline$>100.000$ & 3 & 55.664 .601 & 50,22 \\
\hline Total & $\mathbf{8 8}$ & $\mathbf{1 1 0 . 8 3 3 . 4 3 5}$ & $\mathbf{1 0 0 , 0 0}$ \\
\hline
\end{tabular}

Fuente: ESAMUR, 2014. Elaboración propia.

La reutilización de las aguas depuradas en regadío ha sido primordial, dada la relevante importancia histórica y socio-económica de la agricultura de Murcia (Morales, 2001; Morales y Vera, 1989). Todas las aguas residuales reciben un tratamiento biológico, conforme con la Directiva Europea 91/271 CEE, contando además con tratamiento terciario de regeneración el $45 \%$ del volumen depurado. En 2002, en Murcia ya se aprovechaba el 100\% de los $60 \mathrm{hm}^{3} /$ año de aguas reutilizadas para uso agrario. En esa fecha ya se atisbaba que la depuración y reutilización con fines agrarios y ecológicos iba a experimentar un impulso durante los próximos años cuando se culminase el Plan de Recuperación de la Calidad del Agua del Río Segura (Olcina, 2002). La alta calidad del agua tratada permite la reutilización en regadío en diferentes zonas de riego y la aportación al río Segura, humedales y cauces, contribuyendo con una aportación de unos 100 $\mathrm{hm}^{3} /$ año (2011), a paliar el déficit del balance hídrico de la cuenca del Segura. La superficie regable en la Región de Murcia era entonces de 154.680 ha, de las cuales, 100.337 ha (el 64,86\%) podían recibir aguas depuradas.

El volumen de residuales aplicadas directamente a riego en la Región de Murcia es de $49 \mathrm{hm}^{3}$, cifra que representa el 42,5\% de reutilización directa en agricultura, del caudal total depurado. En el año 2012 se produce un descenso de forma generalizada en los volúmenes de efluente prácticamente en la totalidad de las EDAR causando un leve descenso del volumen reutilizado directamente en agricultura. Este mismo año, de los $109,4 \mathrm{hm}^{3}$ depurados, $47,18 \mathrm{hm}^{3}$ son de reutilización directa (el $42,51 \%$ ). Un $49,57 \%$ son reutilizadas indirectamente mediante vertido a cauce público, de ahí que gran parte de esos recursos pueda ser derivado para riego en varios ciclos de uso aguas abajo del punto de vertido, a través de las redes de aguas vivas y muertas de la Vega del Segura. El 7,9\% son aguas no utilizadas para riego, siendo su destino a infiltración o directamente al mar. El volumen máximo de agua reutilizada para riego se registró en 2010 con $50,33 \mathrm{hm}^{3}$. 
Producción y uso de aguas regeneradas por zonas geográficas

Para una mejor comprensión de la situación en la que se encuentra la depuración en la Región de Murcia se ha zonificado su territorio en diferentes áreas (Tabla 5). Por instalaciones de depuración disponibles, destacan tres áreas con población superiores a los 150.000 habitantes como son la Vega Alta del Segura, la Huerta de Murcia y el Campo de Cartagena.

Tabla 5. Distribución de las depuradoras por zonas en la Región de Murcia

\begin{tabular}{|l|c|r|r|c|}
\hline \multicolumn{1}{|c|}{ Zona } & N. $^{\mathbf{0}}$ Municipios & $\begin{array}{c}\text { Población } \\
\text { (INE 2012) }\end{array}$ & $\begin{array}{c}\text { Superficie } \\
(\mathbf{K m})\end{array}$ & $\begin{array}{c}\text { N. }{ }^{\mathbf{0}} \text { EDAR } \\
(\mathbf{2 0 1 2})\end{array}$ \\
\hline Noroeste & 5 & 73.935 & $2.380,60$ & 9 \\
\hline Altiplano & 2 & 60.312 & $1.573,70$ & 7 \\
\hline Cuenca del Mula & 4 & 24.643 & 727,80 & 6 \\
\hline Vega Alta del Segura & 13 & 195.1449 & $1.029,70$ & 10 \\
\hline Levante & 3 & 32.376 & 429,30 & 8 \\
\hline Alto Guadalentín & 2 & 107.607 & $1.820,00$ & 7 \\
\hline Bajo Guadalentín & 4 & 57.331 & 706,60 & 6 \\
\hline Huerta de Murcia & 3 & 493.933 & 912,30 & 15 \\
\hline Águilas y Mazarrón & 2 & 70.236 & 570,70 & 3 \\
\hline Campo de Cartagena & 3 & 266.741 & $1.021,20$ & 10 \\
\hline Mar Menor & 4 & 92.186 & 142,00 & 5 \\
\hline Total & $\mathbf{4 5}$ & $\mathbf{1 . 4 7 4 . 4 4 9}$ & $\mathbf{1 1 . 3 1 3 , 9 0}$ & $\mathbf{8 6}$ \\
\hline
\end{tabular}

Fuente: ESAMUR, 2012.

La Vega Alta es la zona que más municipios aglutina, un total de 13, que se disponen a lo largo del cauce del río Segura. Esta cercanía al río hace de este tramo el de mayor fragilidad para la calidad de sus aguas si no se consigue una depuración óptima de residuales. Aunque la mayoría de la población se concentra en los núcleos urbanos, también existe un poblamiento disperso que merma la eficacia de la depuración. Por otro lado, la red de saneamiento también puede recibir agua procedente de drenajes agrícolas, riegos, etc., que acaba por incrementar el caudal recibido por las EDAR. Estas afecciones se incrementan en la aglomeración urbana de Murcia, cuyo crecimiento se ha producido sobre la antigua Huerta. La mayor parte de municipios cuentan con EDAR propia para depurar sus residuales, pero algunos de menor tamaño suelen enviar sus aguas a otras depuradoras cercanas.

En la Vega Alta del Segura los cultivos de regadío suman 21.343 ha, de las cuales más del 60\% pueden regarse con aguas regeneradas, que en 2012 
tuvieron un consumo de $9.873 .087 \mathrm{~m}^{3}$. Esta reutilización directa constituye el $63,6 \%$ del agua regenerada, siendo el 51\% procedente de la EDAR de Molina de Segura. En la zona de la Huerta de Murcia, con una superficie agrícola de 21.918 ha, la EDAR de Murcia vierte sus aguas al río Segura, y la de El Raal al Meranche de los Giles, reutilizándose indirectamente para el riego. El agua del resto de las plantas se destina directamente al riego, empleándose en 2012 un total de $4.164 .701 \mathrm{~m}^{3}$. La zona del Campo de Cartagena engloba los municipios de Cartagena, Torre-Pacheco y Fuente Álamo. El principal suministro de agua para riego de la zona es el Trasvase Tajo-Segura, complementándose con aportaciones de aguas subterráneas y regeneradas. La superficie destinada a la agricultura en el Campo de Cartagena supera las 33.000 ha, y en 2012 el volumen de regenerada destinado a riego fue de $12.798 .970 \mathrm{~m}^{3}$, lo que corresponde al 92,3\% del agua depurada.

La distribución de estos recursos se rige por el régimen concesional establecido por la Confederación Hidrográfica del Segura. Las zonas donde más volumen de agua regenerada se utiliza para regadío es el Campo de Cartagena con el $28,6 \%$ del total de la Región de Murcia $\left(12,79 \mathrm{hm}^{3}\right)$, la Vega Alta del Segura con el $22,1 \%\left(9,87 \mathrm{hm}^{3}\right)$, y en tercer lugar, la Huerta de Murcia con el $9,3 \%\left(4,16 \mathrm{hm}^{3}\right)$. En relación con las zonas que menos agua reutilizan destaca la zona del Mar Menor con 3,69 $\mathrm{hm}^{3}$, que representa el 47,42\% del volumen de agua depurada de esta área. Las zonas que más reutilizan en comparación con el total depurado son el Campo de Cartagena con 12,79 $\mathrm{hm}^{3}$ (el 92,3\%), el Alto Guadalentín con 3,46 hm ${ }^{3}$ (el 96,35\%), y el Bajo Guadalentín con 2,74 $\mathrm{hm}^{3}$ (el 96,8\%). Actualmente, dado el tipo de productos agrarios que demandan los mercados, especialmente en el apartado de calidad y aspectos fitosanitarios, la agricultura de regadío que se sirva de este tipo de recursos debe contar con aguas que, al menos, tengan, escasa turbidez, una salinidad por debajo de los $750 \mathrm{mg} . / \mathrm{l}$. y una reducción adecuada de los contenidos de boro (Rico et al., 1998).

Las aguas residuales industriales conectadas a las redes de alcantarillado tienen su origen fundamentalmente en la industria alimentaria y específicamente en la de conserva vegetal. Es de notar que este sector ha mejorado sustancialmente en los últimos años sus instalaciones de prevención de contaminación en origen. Cabe destacar el esfuerzo realizado por la administración murciana para mejorar la calidad de las aguas vertidas al Mar Menor, zona catalogada «sensible» según contempla la Directiva Europea 91/271. En el marco de la Ley del Mar Menor (Ley 3/1987 de 23 de abril, sobre Protección y Armonización de Usos del Mar Menor) se puso en marcha el «Plan de Saneamiento de aguas residuales», con apoyo financiero de la Unión Europea, dentro de su programa ENVIREG, y fondos de la comunidad autónoma, con el objetivo de perseguir un vertido cero en este mar interior. Atendiendo a los datos de Comisaría de Aguas de la 
Confederación Hidrográfica del Segura, de las concesiones de aguas depuradas en la Región de Murcia, a la fecha de 17 de abril de 2013, se observa que varias EDAR de urbanizaciones, algunas del tipo residencial «resort», contaban con depuración cuyo producto tratado se empleaba en el riego de los propios espacios verdes. Así sucede con las urbanizaciones de Mosa Trayectum, Inmogolf Los Belones, Nova Cartago, Mar Menor Golf, etc. Algunas aguas depuradas de EDAR de industrias se aplican en el entorno rural de las mismas como Factoría El Pozo, en Alhama de Murcia; también ayuntamientos como el de Molina de Segura, que usaba una parte de las aguas tratadas de la EDAR Norte para el riego del parque urbano de «La Compañía» (Pérez et al., 2014).

\section{Gestión y aprovechamiento de lodos de depuración y de biogás}

En Murcia se sigue el mismo principio de reutilización de los lodos de depuración que se usa en la reutilización de las aguas procedentes de EDAR urbanas. Estos lodos son una fuente de materia orgánica y de elementos fertilizantes para los terrenos agrícolas, especialmente los catalogados como residuos no peligrosos que, suministrados con el control adecuado, suponen un aporte nutricional para los cultivos agrícolas, a la vez que contribuyen a la recuperación de suelos degradados por pérdida de materia orgánica. El sistema de gestión implantado por ESAMUR permite la trazabilidad de todas y cada una de las partidas de lodo aplicado al suelo desde su producción hasta su aplicación agrícola. La Región de Murcia, en 2011, contaba con una superficie de suelo agrícola seleccionado y autorizado para la aplicación de lodos en 2.302,21 ha. En ese mismo año se aplicaron $87.459 .110 \mathrm{~kg}$ de lodo en zonas agrícolas, incrementándose en 2012 hasta $97.840 .665 \mathrm{~kg}$ de materia húmeda, siendo las zonas del Bajo Guadalentín y la Cuenca del Mula donde se aplica más del $50 \%$ de estos lodos. La normativa que regula las características de calidad necesarias para el uso de los lodos de depuración viene recogida en el Real Decreto 1310/1990.

En algunas EDAR, concretamente en las de mayor tamaño, que poseen digestión anaerobia de los fangos, se aprovecha el biogás generado para la obtención de energía y calor, que se genera en el circuito de refrigeración y en el de los gases de escape. Éste se emplea para calentar el fango durante el proceso de digestión, y la energía obtenida se puede emplear tanto para autoconsumo como para su venta a la red eléctrica. Este biogás está compuesto principalmente de metano y dióxido de carbono, y se llega a producir, por cada kilogramo de materia volátil eliminada, entre 0,8 y $1,1 \mathrm{~m}^{3}$ de gas, con un poder calorífico que oscila entre 4.500 y $6.000 \mathrm{kcal} / \mathrm{m}^{3}$. Con este aprovechamiento también se eliminan componentes perjudiciales. En 2012 la Región de Murcia disponía de 5 plantas que cuentan con aprovechamiento de biogás mediante cogeneración eléctrica. La potencia total instalada en equipos de cogeneración es de 2,9 MW 
eléctrico, siendo su producción anual de 11,5 GWh eléctricos, lo que equivale al consumo eléctrico anual de unas 3.200 viviendas. Además una de estas EDAR, concretamente la de Molina de Segura, está empleando desde hace unos años melazas y lixiviados de vertedero, que ayudan a incrementar la producción de biogás.

Figura 2. Áreas de uso atendidas con aguas residuales regeneradas en las regiones de Murcia y Valencia

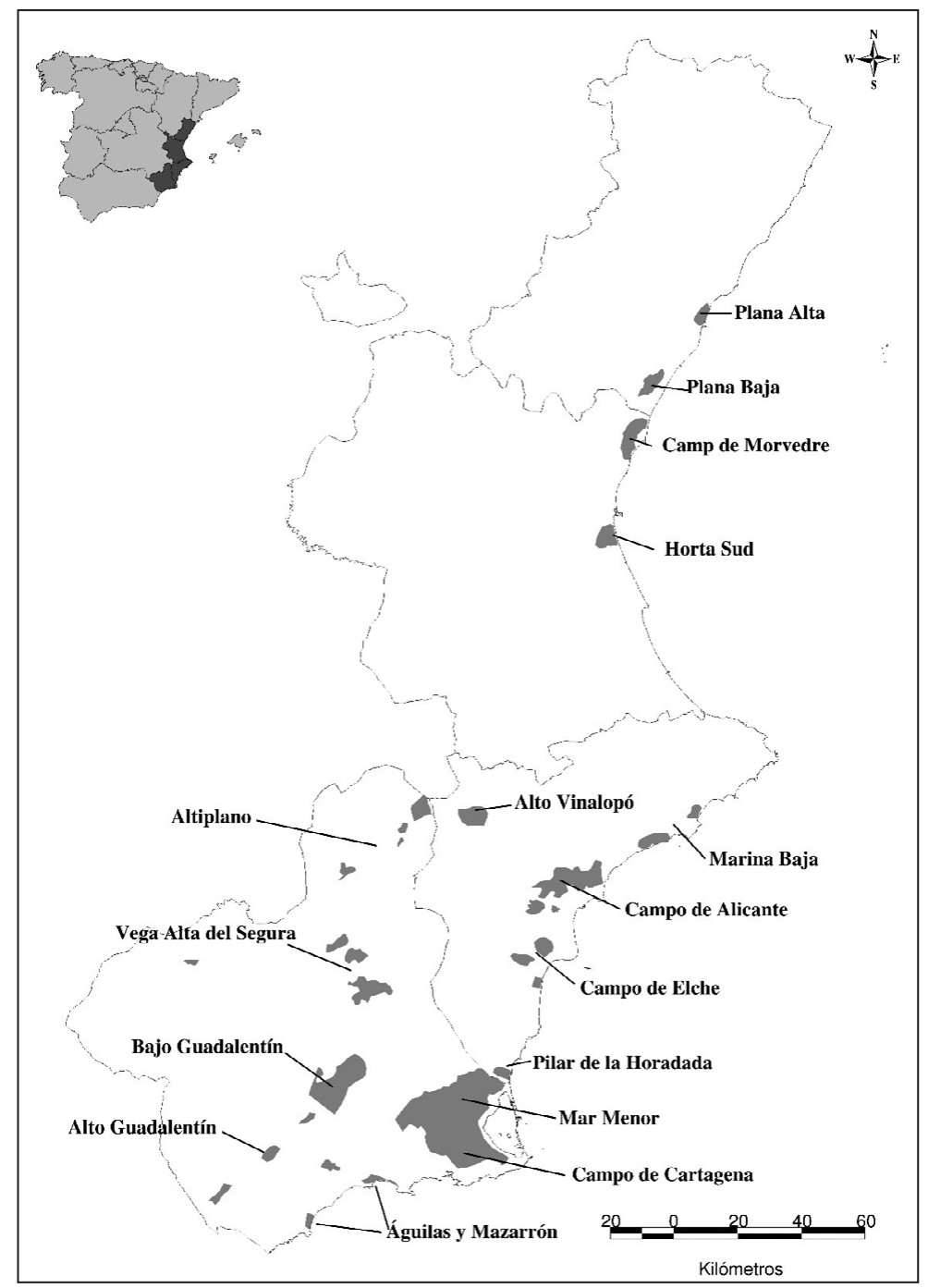

Fuente: Elaboración propia. 
DEPURACIÓN Y REUTILIZACIÓN DE AGUAS RESIDUALES EN LA COMUNIDAD VALENCIANA

Los avances producidos en materia de depuración: el I y II Plan Director de Saneamiento y Depuración (1992/2003)

La depuración de residuales en la región valenciana ha experimentado una evolución favorable durante las dos últimas décadas atendiendo al grado de cobertura de poblaciones, volúmenes tratados y cumplimiento de la Directiva CEE 91/271. Hito decisivo fue la ejecución del Plan Director de Saneamiento y Depuración (1992) que, a su vez, desarrollaba la Ley de Saneamiento de las Aguas Residuales de la Comunidad Valenciana (Ley 2/1992, de 26 de marzo), que supuso también la creación de la Entidad Pública de Saneamiento de Aguas Residuales (EPSAR). En una primera fase (1992/93), se primaron las actuaciones en municipios con población superior a 10.000 habitantes, y en una segunda etapa, hasta 2005, se orientaron a corregir los problemas de depuración y saneamiento de poblaciones con menos de 2.000 habitantes, incluyendo también la construcción de pequeñas plantas en urbanizaciones y zonas residenciales del litoral que carecían de dicho servicio básico. En ambas etapas, el nivel general de tratamiento más utilizado fue el secundario (biológico), y a partir de 2005, se inició un nuevo ciclo que ha potenciado los sistemas terciarios, incluyendo en ocasiones desalinización, para favorecer una mayor reutilización de los caudales regenerados en usos agrícolas, urbanos y recreativos.

Para financiar esas actuaciones, la indicada Ley 2/1992, estableció un canon de saneamiento cuyos rendimientos se destinan a garantizar el funcionamiento de las instalaciones de depuración existentes, así como a contribuir a la financiación de otras nuevas. El importe de dicho canon viene referido al volumen de agua consumido en usos urbanos (domésticos, comerciales, industriales), y en su cómputo puede diferenciarse la población atendida y la carga contaminante generada. Por dicho canon, EPSAR ingresó en 2014, más de 265 millones de $€$, con los que se afrontaron los costes de explotación de las depuradoras (148 millones de $€$ ), construcción de nuevas instalaciones (39 millones de $€$ ) y otros gastos de personal, etc.

El coste medio de tratamiento del agua residual en la región valenciana durante 2014 fue de $0,34 € / \mathrm{m}^{3}$, y el canon de saneamiento y depuración ha adquirido un peso creciente y muy relevante en la factura del agua potable que pagan los ciudadanos, donde se incluye una cuota por el uso del alcantarillado y otra por el canon de saneamiento. La evolución de dichos conceptos puede valorarse analizando un caso práctico de factura de agua potable, en una vivienda de la ciudad de Alicante, comparando el año 2000 y el 2014. En 2000, y con un consumo trimestral de $30 \mathrm{~m}^{3}$, la factura ascendía a $37,75 €$, es decir, a un coste medio de $1,25 € / \mathrm{m}^{3}$, donde el servicio de alcantarillado y el canon 
de saneamiento, contribuían con un $37 \%$ al importe final. En 2014, con un consumo idéntico, la factura final del agua potable, crecía a $67 €$, con un coste medio de $2,23 € / \mathrm{m}^{3}$, y la participación del servicio de alcantarillado y el canon de saneamiento creció al 42,3\%, en dicho importe final. Las tarifas del canon incluyen una cuota de servicio y otra de consumo, y varía según usos (urbano e industrial) y por tamaño poblacional del municipio atendido. Así, con tarifas de 2014, en un municipio con más de 50.000 habitantes la cuota de consumo ascendía a $0,42 € / \mathrm{m}^{3}$ y la de servicio a $43,52 € /$ año, frente a los $0,31 € / \mathrm{m}^{3}$ y 31,49 $€ /$ año de otro con menos de 3.000 habitantes. En cambio, los usos industriales afrontaban una cuota de consumo fija de $0,55 € / \mathrm{m}^{3}$ y otra de servicio variable según calibre del contador, que puede llegar a $3.952 € /$ año, si éste supera los 80 mm (EPSAR, 2014).

El Plan Director de Saneamiento y Depuración (1992), incluía una valoración del estado de funcionamiento en que se encontraban las 365 depuradoras existentes en la región. El $46 \%$ de esas instalaciones no funcionaba, y las restantes lo hacían de forma muy precaria, con diseños obsoletos y de tipo primario, que incumplían la Directiva Comunitaria 91/271. Tras la creación de la EPSAR las primeras actuaciones se dirigieron a la construcción de nuevas instalaciones, principalmente en grandes ciudades y aglomeraciones urbanas, si bien, en 1997, con 225 depuradoras en funcionamiento, el volumen depurado creció a $305 \mathrm{hm}^{3}$, frente a los $269 \mathrm{hm}^{3}$ de 1993, cuando en esos años deberían tratarse alrededor de $500 \mathrm{hm}^{3} /$ año considerando los datos de consumo de agua potable a escala regional. Esa situación también se sufría en otras regiones, debido a que muchos núcleos urbanos no contaban ni con red de saneamiento ni con depuradoras; en otros casos las instalaciones existentes funcionaban de forma muy deficiente, y residuales sin depurar se vertían a pozos ciegos y cauces públicos. Por esa razón, los datos de volumen depurado no coincidieron con los consumos reales de agua potable al menos hasta 2004, cuando por primera vez se depuraron más de $500 \mathrm{hm}^{3}$. Este nivel de depuración se mantuvo estable hasta 2010 (502 $\mathrm{hm}^{3}$ ), para descender a partir de entonces por la reducción del consumo de agua potable que se ha producido en la región valenciana por efecto de una amalgama de causas estructurales y coyunturales donde intervienen la crisis económica, la instalación de nueva grifería y electrodomésticos más eficientes en el gasto de agua y energía, y todo ello unido a una mayor concienciación en el ahorro hídrico. Así, a partir de 2011 esta tendencia se ha dejado sentir en el volumen de agua depurada, que se ha reducido a $474 \mathrm{hm}^{3}$ en dicho año, y a $420 \mathrm{hm}^{3}$ en 2014 , si bien, la capacidad de depuración y regeneración de agua residual, medida en habitantes equivalente (h-e), se ha duplicado durante las dos últimas décadas.

El I y el II Plan Director de Saneamiento y Depuración marcaron como principal objetivo cumplir con las Directivas Comunitarias 91/271/CE y 98/15/CE sobre saneamiento y depuración, que establecieron un calendario de obligado 
cumplimiento, según el cual antes de 31 de diciembre de 2005, tendrían que contar con depuradoras de tipo secundario todos los núcleos urbanos con más de 2.000 habitantes equivalente (h-e) en aguas continentales, y mayores de 10.000 (h-e) en aguas costeras. El parámetro (h-e) equivale a 200 litros de agua residual al día, o a una contaminación de 60 gramos de $\mathrm{DBO}_{5}$ por día. Las actuaciones promovidas a partir de estos planes, han situado a la Comunidad Valenciana junto a Cataluña, Madrid, Baleares y Murcia entre las primeras regiones españolas en el cumplimiento de la Directiva Comunitaria 271/91, con un grado de conformidad que ha crecido del $90 \%$ hace una década a más del $99 \%$ en 2014. El número de depuradoras no ha dejado de crecer, de forma que las 225 instalaciones existentes en 1997, crecieron a 344 en 2000; 409 en 2005; y 466 en 2014. El número de depuradoras se ha duplicado, al igual que ha ocurrido con la capacidad de tratamiento y eliminación de la contaminación, medida en habitantes equivalente. Así dicha capacidad se situaba en 4.400.000 h-e en el año 2000, para aumentar a 6.500 .000 h-e en 2005 y a más de 10.650 .000 h-e en 2014. Esa mayor capacidad también ha permitido elevar el rendimiento medio de la depuración y de los caudales tratados, con valores inferiores a los fijados por la Directiva 91/271, tanto en Solidos Suspendidos (SS), como para $\mathrm{DBO}_{5}$ y DQO. Por ejemplo, el rendimiento de eliminación de $\mathrm{DBO}_{5}$ se sitúa en la Comunidad Valenciana, en valores superiores al $97 \%$, por encima el $70 \%$ que establece la directiva europea, si bien, cabe hacer notar que ello no significa que el caudal tratado cumpla ya de entrada las exigencias de calidad requeridas para su retorno al ciclo hidrológico o para una potencial reutilización.

Tabla 6. Volumen depurado y reutilizado en la Comunidad Valenciana en $2014\left(\mathrm{~m}^{3}\right)$

\begin{tabular}{|c|c|c|c|c|}
\hline PROVINCIA & COMARCA & $\begin{array}{c}\text { Caudal } \\
\text { depurado } \\
\left(\mathrm{m}^{3} / \mathbf{a n n o}\right)\end{array}$ & $\begin{array}{c}\text { Reutilización } \\
\text { directa (mªñano) }\end{array}$ & $\begin{array}{c}\text { Reutilización } \\
\text { indirecta }\left(\mathrm{m}^{3}\right) \\
\text { año) }\end{array}$ \\
\hline \multirow[t]{10}{*}{ Alicante } & L'Alacantí & 27.324 .705 & 9.209 .951 & 2.644 .835 \\
\hline & L'Alcoià & 7.740 .778 & 1.536 .144 & 6.204 .634 \\
\hline & Alto Vinalopó & 2.923 .947 & 2.801 .295 & 122.652 \\
\hline & Bajo Segura & 21.729 .546 & 18.471 .900 & 3.257 .646 \\
\hline & Bajo Vinalopó & 12.930 .596 & 12.662 .550 & 268.046 \\
\hline & El Comtat & 5.649 .925 & 184.257 & 5.465 .668 \\
\hline & Marina Alta & 13.800 .789 & 531.427 & 3.377 .736 \\
\hline & Marina Baja & 20.085 .169 & 7.254 .894 & 3.573 .490 \\
\hline & Medio Vinalopó & 7.147 .489 & 2.553 .993 & 4.593 .496 \\
\hline & Total & 119.332 .944 & 55.206 .411 & 29.508 .203 \\
\hline
\end{tabular}




\begin{tabular}{|l|l|r|r|r|}
\hline Castellón & Alto Palancia & 2.221 .144 & 0 & 2.221 .144 \\
\cline { 2 - 5 } & Alt Maestrat & 643.084 & 0 & 643.084 \\
\cline { 2 - 5 } & Alto Mijares & 544.368 & 0 & 544.368 \\
\cline { 2 - 5 } & L'Alcalatén & 961.092 & 102 & 960.990 \\
\cline { 2 - 5 } & Baix Maestrat & 11.033 .277 & 58.334 & 1.380 .465 \\
\cline { 2 - 5 } & Els Ports & 253.141 & 253.141 & 253.141 \\
\cline { 2 - 5 } & Plana Alta & 23.421 .931 & 1.971 .890 & 2.652 .797 \\
\cline { 2 - 5 } & Plana Baixa & 13.542 .921 & 2.165 .640 & 7.078 .920 \\
\cline { 2 - 5 } & Total & $\mathbf{5 2 . 6 2 0 . 9 5 8}$ & $\mathbf{4 . 1 9 5 . 9 6 6}$ & $\mathbf{1 5 . 7 3 4 . 9 0 9}$ \\
\hline
\end{tabular}

Volumen depurado y reutilizado en la Comunidad Valenciana en $2014\left(\mathrm{~m}^{3}\right)$ (continuación)

\begin{tabular}{|c|c|c|c|c|}
\hline \multirow[t]{18}{*}{ Valencia } & $\begin{array}{l}\text { Rincón de } \\
\text { Ademuz }\end{array}$ & 358.874 & 7.303 & 351.571 \\
\hline & $\begin{array}{l}\text { La Vall } \\
\text { d'Albaida }\end{array}$ & 7.865 .294 & & 7.865 .294 \\
\hline & Ribera Alta & 20.897 .478 & & 18.261 .222 \\
\hline & \begin{tabular}{|l|} 
Valle de \\
Cofrentes
\end{tabular} & 862.078 & 76.700 & 785.378 \\
\hline & Ribera Baixa & 14.593 .699 & 11.429 .172 & 3.164 .527 \\
\hline & \begin{tabular}{|l|} 
Canal de \\
Navarrés
\end{tabular} & 1.395 .020 & 155.958 & 1.239 .062 \\
\hline & Campo de Turia & 9.511 .780 & 40.660 & 9.471 .120 \\
\hline & $\begin{array}{l}\text { Camp de } \\
\text { Morvedre }\end{array}$ & 6.703 .663 & 146.614 & 5.310 .574 \\
\hline & Hoya de Buñol & 3.168 .704 & 622.220 & 2.546 .484 \\
\hline & Los Serranos & 1.918 .480 & 683.727 & 1.234 .753 \\
\hline & Utiel-Requena & 3.168 .240 & 274.941 & 2.893 .299 \\
\hline & La Safor & 16.770 .260 & 825.723 & 2.874 .665 \\
\hline & La Costera & 6.412 .707 & 68.282 & 6.344 .425 \\
\hline & \begin{tabular}{|l|} 
Valencia \\
\end{tabular} & 115.373 .571 & 48.057 .477 & 0 \\
\hline & Horta Nord & 21.944 .536 & 7.743 .366 & 10.242 .946 \\
\hline & Horta Oest & 16.840 .885 & 16.248 .380 & 592.505 \\
\hline & Horta Sud & 690 & & 690 \\
\hline & Total & 247.785 .959 & 86.380 .523 & 73.178 .515 \\
\hline C.Valenciana & \begin{tabular}{|l|} 
Total \\
\end{tabular} & 419.739 .861 & 145.782 .900 & 118.421 .627 \\
\hline
\end{tabular}

Fuente: Entidad Pública de Saneamiento de Aguas Residuales, 2015. 
Tras el proceso de tratamiento, además del agua depurada se obtienen unos lodos con alto contenido en materia orgánica y nutrientes. La generación de lodos depende del volumen de residual depurada y alcanzó un valor máximo en 2005 con $500.000 \mathrm{Tm}$, pero se redujo a partir de 2010 (427 Tm), para alcanzar las $360.000 \mathrm{Tm}$ en 2014. En este último año, alrededor del $88 \%$ de los lodos producidos se emplearon como fertilizantes agrícolas, previo secado térmico, en una extensión estimada superior a las 14.000 ha, y otro $12 \%$ de los fangos fueron valorizados energéticamente en los hornos de cementeras situadas en Alicante y Sagunto (EPSAR, 2014).

El sistema de poblamiento valenciano, aunque manifieste cierto equilibrio espacial por el desarrollo de ciudades medias en algunos valles y comarcas interiores como el Vinalopó, L'Alcoià, Comtat o la Vall d'Albaida, se encuentra fuertemente concentrado en planas costeras, valles litorales y prelitorales que acogen alrededor del $75 \%$ de la población. Este factor explica la distribución espacial de las depuradoras, particularmente de las más grandes, y también de los volúmenes producidos. Es de notar que del recurso tratado en 2014, con 420 $\mathrm{hm}^{3}$, más del $80 \%$ fue producido en esa dorsal de poblamiento, destacando el área metropolitana de Valencia $\left(155 \mathrm{hm}^{3}\right)$, Ribera Alta y Baixa del Júcar (35 $\left.\mathrm{hm}^{3}\right)$, La Safor $\left(16 \mathrm{hm}^{3}\right)$, Plana Alta y Baixa de Castellón $\left(37 \mathrm{hm}^{3}\right)$, L'Alacantí $\left(27 \mathrm{hm}^{3}\right)$, Marinas Alta y Baja $\left(34 \mathrm{hm}^{3}\right)$, y Bajo Vinalopó y Bajo Segura (34 $\left.\mathrm{hm}^{3}\right)$. Con esta concentración de las principales áreas de generación de residuales en comarcas costeras, las posibilidades de reutilización de estos recursos se hallan supeditadas a dos condicionantes de primer orden. En primer lugar, la proximidad de áreas de uso agrícolas, urbanas o recreativas que demanden esos recursos regenerados; $\mathrm{y}$ en segundo término, la capacidad que tienen los futuros usuarios para asumir los costes de captación, bombeo, transporte y tratamientos adicionales para mejorar la calidad del agua si ello fuera preciso.

\section{La reutilización de residuales regeneradas: balance de las iniciativas más destacadas en territorio valenciano}

La Comunidad Valenciana, junto a las regiones de Murcia, Canarias y Baleares, ocupa lugar destacado en España en materia de reutilización de residuales. A mediados de la década de los noventa el uso de residuales ascendía a $120 \mathrm{hm}^{3} /$ año, es decir, un $46 \%$ del caudal que se depuraba entonces. De dicho volumen aprovechado, un $65 \%$ era consumido para riego agrícola y de campos de golf, en las comarcas alicantinas del Vinalopó, Marina Baja y Bajo Segura, mientras que su consumo era poco significativo en las provincias de Valencia y Castellón. En 2005, se aprovecharon unos 235 hm³/año, de los cuales unos 165 $\mathrm{hm}^{3} /$ año corresponden a reutilización directa y el volumen restante a indirecta. En la actualidad, según datos de 2014 facilitados por EPSAR, el volumen de 
residuales regeneradas aprovechado ha crecido a más de $266 \mathrm{hm}^{3}$ que representaba alrededor del $63 \%$ del agua depurada en dicho año. Es de notar que de dicho volumen aprovechado, unos $146 \mathrm{hm}^{3}$ corresponden a reutilización directa, y el resto a indirecta (vertido a cauces e infiltración en acuíferos).

Uno de los factores decisivos a considerar en la reutilización de residuales es la calidad que ofrece el recurso regenerado, particularmente cuando una deficiente calidad con valores de alta conductividad, presencia de coliformes o elementos sensibles como el boro, puede afectar seriamente a cultivos de cítricos y hortícolas, con incumplimiento incluso de normas sanitarias. A su vez, la calidad del recurso obtenido depende directamente del tipo de tratamiento, tamaño y rasgos técnicos de la depuradora, pero el coste medio del agua regenerada con sistema secundario en la Comunidad Valenciana ronda los $0,33 € /$ $\mathrm{m}^{3}$, pero oscila de $0,14 € / \mathrm{m}^{3}$ en las plantas de mayor tamaño, a $1 € / \mathrm{m}^{3}$ en las más pequeñas. No obstante, la mayor calidad del agua regenerada se obtiene con tratamientos terciarios más avanzados que incluyen rayos ultravioleta, ultrafiltración e incluso desalinización, los que permite reducir los valores de nitrógeno, fósforo, boro, eliminar prácticamente los coliformes, y también disminuir la alta conductividad. No obstante, el coste de este tipo de tratamientos más avanzados, oscila de 0,28 a $0,30 € / \mathrm{m}^{3}$, y considerando que el agua ha de ser tratada previamente en la línea de secundario, el coste final del recurso que se obtiene a pié de depuradora puede variar de 0,42 a $0,44 € / \mathrm{m}^{3}$, y ello sin incluir los costes de bombeo y elevación a las respectivas áreas de uso. Para superar las reticencias de regantes y de otros posibles usuarios en materia de calidad del recurso regenerado, la Generalidad Valenciana ha realizado grandes inversiones para mejorar las infraestructuras de depuración, con una implantación progresiva de sistemas terciarios y avanzados, que se disponen ya en 41 depuradoras que suman una capacidad total de tratamiento de $333 \mathrm{hm}^{3} / \mathrm{año}$. Entre las instalaciones de mayor tamaño que cuentan con terciario destacan Pinedo, con 127 $\mathrm{hm}^{3} /$ año; y las EDAR de Benidorm y Rincón de León, en Alicante, equipadas con ultrafiltración y desalinización, con una capacidad total de $22,6 \mathrm{hm}$ 3/año (EPSAR, 2014).

La distribución geográfica de las áreas de uso de aguas depuradas, revela que son las provincias de Valencia y Alicante, las que más recursos aprovechan, con 159 y $84 \mathrm{hm}^{3}$ respectivamente, en 2014. En cambio, en Castellón tan sólo se emplearon unos $20 \mathrm{hm}^{3}$, de los cuales tan sólo $4,2 \mathrm{hm}^{3}$, correspondían a reutilización directa, lo que representa alrededor del $8 \%$ del volumen depurado $\left(52,6 \mathrm{hm}^{3}\right)$. En esta provincia domina la reutilización indirecta $\left(15,7 \mathrm{hm}^{3} /\right.$ año $)$, que suele aprovecharse para el llenado de marjales y, con ello, para la recarga inducida de los acuíferos costeros. En uso directo de residuales, tan sólo destacan algunas iniciativas en Castellón, Villarreal y la Vall de Uxó, sobre todo para el riego de cítricos. 
La provincia de Valencia es la que alcanza un mayor volumen de reutilización directa, con $86 \mathrm{hm}^{3}$ consumidos en 2014, especialmente con destino a cítricos y arrozal, en diferentes municipios de la Ribera Baixa y, sobre todo, en el área de la antigua Huerta de Valencia, merced a los caudales generados en el área metropolitana, que aportan más de $71 \mathrm{hm}^{3}$. La aplicación de ayudas FEDER para la ampliación de la depuradora de Pinedo, que cuenta con una capacidad de producción de residuales depuradas que supera los $125 \mathrm{hm} /$ año, ha permitido incorporar el tratamiento terciario y la obtención de un recurso de mayor calidad para su uso en los regadíos de la Huerta de Valencia y en el Parque Natural de la Albufera. El proyecto se acompañó de una red de distribución que permite conectar la planta de Pinedo para destinar hasta $70 \mathrm{hm}^{3} /$ año a los regadíos de la Acequia del Oro, Favara, parte de la Acequia Real del Júcar (ARJ) y algunos sectores del canal Júcar-Túria, para el riego de cítricos y arrozal, con un coste muy reducido y, más aún, con una gran garantía de suministro, incluso durante situaciones de sequía. Se pretendía también derivar $50 \mathrm{hm}^{3} /$ año para alimentar el Parque Natural de la Albufera, para evitar los riesgos de eutrofización y reducir los niveles de fósforo y de nitrógeno del agua depurada antes de su vertido al lago, se experimentó con un sistema de filtro verde en el cauce del Turia, que finalmente ha sido abandonado tras una inversión superior a los dos millones de euros.

En la provincia de Alicante hace más de tres décadas que se recurre a las residuales depuradas para satisfacer demandas agrícolas, con planteamientos técnicos que revisten carácter pionero a escala internacional. De los $119 \mathrm{hm}^{3}$ que se depuraron en 2014, 55,3 $\mathrm{hm}^{3}$ fueron objeto de reutilización directa, y otros $29,5 \mathrm{hm}^{3}$ de reutilización indirecta, lo que representa más del $71 \%$ sobre el caudal total regenerado. Diferentes entidades de regantes tienen concedido un volumen que supera los $70 \mathrm{hm}^{3} /$ año, mientras que en el riego de campos de golf, jardines y medianas de carreteras se consumen otros $4 \mathrm{hm}^{3} /$ año (Rico et al., 1998). Las iniciativas de reutilización más destacadas se encuentran en las comarcas del Vinalopó, Campo de Alicante, Marina Baja y Bajo Segura, donde abundan las depuradoras sometidas a un intenso aprovechamiento de residuales. Por ejemplo, la Comunidad General de Usuarios del Alto Vinalopó ha establecido como objetivo prioritario en sus actuaciones la preservación de los acuíferos, lo que incluye el uso integral de todos los recursos que aporta la depuradora de Villena, que a su vez regenera también las residuales de los municipios de La Cañada y Campo de Mirra. Asimismo, reviste carácter prototípico el complejo hidráulico construido en 1980 por el IRYDA en el Medio Vinalopó y Campo de Alicante, que permite elevar mediante varias impulsiones que suman 400 metros, las aguas de la depuradora del Rincón de León (Alicante) a las áreas de riego de Agost y Monforte del Cid, con unos costes de bombeo próximos a 0,18 $€ / \mathrm{m}^{3}$ que asumen íntegramente los agricultores. 
En la comarca de L'Alacantí, Aguas Municipales de Alicante Empresa Mixta (AMAEM) ha desarrollado durante la última década, una de las iniciativas más destacadas de España en materia de reutilización de residuales en usos urbanos, particularmente en riego de parques y jardines. La mayor progresión de esta fuente no convencional tuvo lugar durante la última sequía de 20052009, al intensificarse su consumo. Por ejemplo, en 2007, el empleo de este tipo de recursos sumaba un volumen de $182.208 \mathrm{~m}^{3}$, de los cuales 180.378 $\mathrm{m}^{3}$ fueron suministrados al ayuntamiento y otros $1.830 \mathrm{~m}^{3}$, a particulares. En 2013, el consumo de aguas regeneradas en la ciudad de Alicante ha crecido a $673.001 \mathrm{~m}^{3}$, de los cuales $587.357 \mathrm{~m}^{3}$, fueron suministrados al ayuntamiento, y otros $85.644 \mathrm{~m}^{3}$ a particulares. Este fuerte ritmo de progresión también se hace patente en la evolución del número de contratos suscritos por AMAEM con el ayuntamiento y particulares, que ha crecido de 8, en 2007, a 90 en 2013. Un factor de demanda que ha propiciado su expansión es la gran diferencia de tarifas existentes entre el agua regenerada, que en 2013 se distribuía a $0,32 € /$ $\mathrm{m}^{3}$, y el agua potable que, por ejemplo, para un consumo de $30 \mathrm{~m}^{3}$ por trimestre puede alcanzar un coste medio de $2,23 € / \mathrm{m}^{3}$.

Los recursos son proporcionados por las líneas de terciario avanzado existentes en las depuradoras de Orgegia (10.000 m³/día) y Rincón de León (2.000 $\mathrm{m}^{3} /$ día). En esta última depuradora que suministra residuales a los regadíos del Campo de Alicante y Vinalopó, se ha implantado un sofisticado sistema de tratamiento terciario, con desalación mediante ósmosis inversa, para producir $25.000 \mathrm{~m}^{3} /$ día de agua desalada más otros $13.000 \mathrm{~m}^{3} /$ día de agua ultrafiltrada. Mediante 4 líneas de ósmosis inversa, se reduce el alto contenido de salinidad $(2.800 \mu \mathrm{s} / \mathrm{cm})$ del agua residual que llega a la depuradora, hasta reducirlo a 600 $\mu \mathrm{s} / \mathrm{cm}$, obteniendo así un recurso de alta calidad para el riego de todo tipo de producciones agrarias. El agua obtenida se destina al riego de parques y jardines de la ciudad de Alicante, si bien, el mayor consumo es el agrícola, que atiende el riego de 6.800 ha de las entidades Aralvi y Agricoop, en el Campo de Alicante y Medio Vinalopó, y también podría atenderse otras 7.000 ha de la Comunidad de Riegos de Levante en el municipio de Elche.

En la ciudad de Alicante, el mayor consumidor es el ayuntamiento, con $587.357 \mathrm{~m}^{3}$ facturados en 2013, con más del $87 \%$ del recurso distribuido en ese año, lo que ha permitido sustituir el consumo de agua potable que era utilizada para el riego de parques y jardines por agua regenerada, que puede conducirse a distintos parques públicos como Benacantil, Vía Parque, Lo Morant y el Tossal.

En relación con el abastecimiento a particulares, se han suscrito 85 contratos de suministro de agua regenerada producida en Monte Orgegia, que cuenta con una línea de terciario de $10.000 \mathrm{~m}^{3} /$ día, que ha permitido extender la red de riego a la zona de Vistahermosa (Calle de la Encina, Manzano, del Chopo, del Sauce, etc.), donde proliferan los chalets con jardín y pequeños huertos. La red también 
ha llegado a la partida de La Condomina (Camino del Ciprés, de La Huerta), y las urbanizaciones de Alicante Golf (urbanizaciones de adosados y campo de golf). Por su parte, desde la EDAR del Rincón de León, también se suministra agua regenerada al parque del Palmeral.

Otra de las iniciativas de reutilización de residuales que reviste carácter pionero a escala internacional es la desarrollada en la Marina Baja. Las depuradas constituyen la piedra angular de un modelo de armonización de usos que permite garantizar el suministro de agua potable del Consorcio de Aguas de la Marina Baja, a partir del intercambio con los regantes de agua depurada por «agua blanca». El aprovechamiento de residuales depende de las coyunturas hidrológicas. En situaciones de bonanza pluviométrica como ocurrió de 2006 a 2013, el consumo de estos recursos descendió a menos de $3 \mathrm{hm} /$ año, con mínimo de $1,5 \mathrm{hm}^{3} /$ año, en 2012. En cambio, el consumo de residuales depuradas, que se ve facilitado por una red de distribución específica por gravedad que parte de la depuradora de Benidorm, crece durante ciclos de sequía, como el sufrido de 1998 a 2002, cuando el Consorcio distribuyó de 9 a 10 hm³ /año para riego, reduciendo con ello la presión sobre el «agua blanca» que se necesita para garantizar el abastecimiento.

La piedra angular de ese modelo es el flujo de reutilización de residuales, integrado en el sistema de explotación del Consorcio, desde 1982, tras la inauguración de la depuradora de Benidorm en Sierra Helada, a 141 m de altitud, que permite enviar, por gravedad y sin coste de bombeo, agua para el riego de 3.700 ha. Esta solución permite el intercambio de aguas blancas por regeneradas, mediante distintas compensaciones a las entidades de regantes, destinando las primeras al abastecimiento y las segundas al riego agrícola, de campos de golf y usos recreativos. Los regantes pueden usar agua blanca y regenerada, modulado el flujo de ambos recursos según la situación hidrológica, y procurando siempre la máxima garantía de suministro para el abastecimiento urbano.

Entre 1990 y 1993, el Consorcio de Aguas de la Marina Baja formalizó los primeros acuerdos con las Comunidades de Regantes del Canal Bajo del Algar (2.500 ha) y de Villajoyosa ( $840 \mathrm{ha}$ ), respectivamente, para favorecer el intercambio de aguas bancas por depuradas, facilitando el uso de infraestructuras comunes (embalses y conducciones), para impulsar un modelo de uso conjunto de aguas superficiales y subterráneas. Además de servir el agua depurada a coste cero, el Consorcio también asumía la construcción de embalses y redes de distribución. Igualmente, a partir de 2006 se implantó el sistema terciario avanzado con ultrafiltración y desalinización en la depuradora de Benidorm, ante las quejas de los regantes que exigían un agua regenerada con óptimas condiciones de calidad para el riego de cítricos y níspero, muy sensibles a la alta conductividad que ofrecía la línea del secundario de la planta de Sierra 
Helada. En este caso, la depuradora de Sierra Helada es explotada por dos empresas distintas, que gestionan respectivamente la línea de secundario y la del terciario avanzado. El agua depurada puede ser vertida al mar (secundario) o suministrada (terciario) al Consorcio de Aguas para su cesión al Canal Bajo del Algar, que es quien suministra agua regenerada para regar los dos campos de golf de Terra Mítica, jardines y pequeños huertos en las zonas residenciales de baja densidad de Benidorm. Acuerdos más puntuales, para situaciones de sequía, también se han pactado con las comunidades de regantes de la Nucía y Altea, también para favorecer el uso de agua depurada reduciendo tensiones con los abastecimientos por el consumo de agua blanca.

En el Bajo Segura, es la ciudad de Torrevieja la que ofrece otro de los ejemplos modélicos de reutilización integral del agua regenerada. Esta localidad, que ha sufrido un aumento exponencial de la población durante las últimas décadas, ha tenido que adecuar sus sistemas de abastecimiento y depuración a estas nuevas demandas. Por ello ha recurrido a esta fuente alternativa que es proporcionada por su EDAR, dotada con sistema terciario. La red de saneamiento de Torrevieja suma $319 \mathrm{~km}$ de longitud y es unitaria, es decir, transporta tanto las residuales y como las pluviales. Estas aguas llegan a la depuradora de Torrevieja que, tras su ampliación entre 2005 y 2007 por la Entidad Pública de Saneamiento de Aguas Residuales de la Comunidad Valenciana (EPSAR), es capaz de tratar hasta $60.000 \mathrm{~m}^{3} /$ día de aguas residuales, adecuándose así a los picos de caudal que puedan sufrir con la llegada de los turistas y dando servicio a un total de 490.000 habitantes equivalentes. Cuenta con un tratamiento terciario que acondiciona el agua regenerada para ser posteriormente empleada para riego de zonas agrícolas, campos de golf, parques y jardines.

La EDAR dispone de 5 líneas de tratamiento biológico, que se ponen en funcionamiento según las variaciones estacionales del caudal. La totalidad del agua depurada es regenerada mediante un tratamiento terciario consistente en una filtración rápida en lechos pulsantes de arena y desinfectada mediante radiación ultravioleta. El 96\% del agua tratada se destina para riego agrícola, mediante concesiones administrativas otorgadas por la Confederación Hidrográfica del Segura a las comunidades de regantes Torremiguel y La Pedrera. El 6\% del agua restante recibe un tratamiento Terciario por Infiltración-Percolación modificada y desinfección por cloración, y posteriormente se reutiliza para uso municipal en riego de parques y jardines, mediante una compleja red de distribución. Las aguas depuradas procedentes de la estación de tratamiento de aguas residuales de Torrevieja son almacenadas temporalmente en un depósito de regulación propiedad de la Comunidad de Regantes de Torremiguel e impulsadas a depósitos intermedios que dicha comunidad tiene distribuidos por el Alto de las Majadas, en el término municipal de Orihuela. 


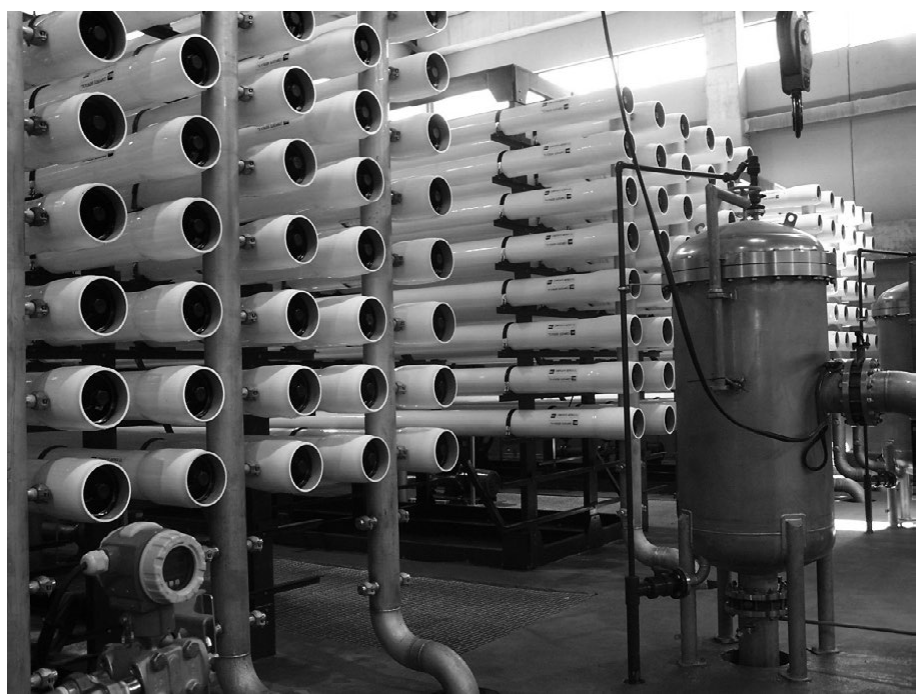

Figura 3. Los avanzados sistemas de tratamiento terciario, con empleo de desalinización, se han implantado en depuradoras de Alicante como Benidorm y Rincón de León. En esta última, con técnica de ósmosis inversa, se producen $25.000 \mathrm{~m}^{3} /$ día de agua residual desalada para el riego de unas 13.800 ha del Vinalopó y Campo de Alicante.

\section{CONCLUSIONES}

En regiones como Murcia y Valencia, la reutilización de aguas residuales constituye una fuente alternativa de extraordinario interés para paliar la escasez natural de agua, los efectos de intensas sequías, y las posibles consecuencias que tendría el cambio climático en áreas mediterráneas. En los usos del agua urbano-turísticos, de gran relevancia para la fachada oriental de la Península Ibérica, los recursos convencionales proporcionados por embalses, acuíferos y trasvases son en principio los de mayor exposición a situaciones de sequía. Frente a ello, el uso de recursos no convencionales (desalinización, pluviales, residuales depuradas) se presenta como una fuente alternativa y de adaptación al régimen de precipitaciones más escasas y erráticas que podría provocar el cambio climático. Por tanto, reviste gran interés conocer y caracterizar estos flujos no convencionales, su aprovechamiento actual, modelo de gestión y su potencial de uso a corto y medio plazo. Igualmente, el uso de aguas regeneradas contribuye ya a satisfacer consumos agrícolas, urbanos y turísticos, reduciendo así el consumo de agua potable y disminuyendo las tensiones y conflictos que surgen entre regantes y abastecimientos durante situaciones de sequía.

Es por ello que la reutilización de aguas residuales constituye un recurso alternativo de vital importancia, aunque podría incrementarse todavía más su nivel de aprovechamiento atendiendo la demanda de determinados usos que, a 
día de hoy, consumen agua potable. En este sentido, usos como los agrícolas, recreativos (campos de golf), urbanos (baldeo de calles y jardines públicos y privados) como ya sucede en determinadas áreas residenciales de la ciudad de Alicante (Vistahermosa) (Gil et al., 2015), e incluso industriales, como ponen de manifiesto los datos de reutilización de aguas regeneradas en la comarca alicantina de l'Alcoià y en la Plana Alta (Castellón). Además, estos recursos cobran un carácter estratégico durante episodios de sequía ya que pueden sustituir determinados usos urbanos y agrícolas ante la escasez de fuentes convencionales, como ha ocurrido con el trasvase Tajo-Segura durante 2015 debido a la sequía de la cabecera del Tajo y a los negativos efectos que ha tenido la modificación de las reglas de explotación y de funcionamiento del acueducto, que se aprobó en el llamado Memorándum, y que ha elevado de 240 a $400 \mathrm{hm}^{3}$ el umbral de «no trasvase» en las reservas almacenadas en los embalses de Entrepeñas y Buendía.

Por regiones, en Murcia, y dada la relevante importancia histórica y socioeconómica que tiene su agricultura de regadío, se considera la reutilización de las aguas depuradas como un pilar fundamental para el mantenimiento de este sector. Al igual que sucede en la Comunidad Valenciana, la Región de Murcia se caracteriza por un alto déficit hídrico que se acentúa con la fuerte producción agrícola y por la intensificación de la demandas de agua para uso urbano-turístico que tuvo lugar de 1980 a 2005. Es por ello que esta región es modélica en la reutilización de aguas depuradas para este fin, ya que el 65\% de las hectáreas regables (unas $100.000 \mathrm{ha}$ ), pueden completar sus dotaciones de recursos convencionales con aguas regeneradas. En 2014 las 88 EDAR de la provincia trataron un total de $104.245 .265 \mathrm{~m}^{3}$, de los cuales se reutilizaron para riego $99.452 .054 \mathrm{~m}^{3}$ (el 95,5\%), vertiéndose al mar sólo el 4,5\% del volumen tratado. Pero este volumen reutilizado no sólo se ha empleado de forma directa sobre el cultivo, sino que también ha vuelto al ciclo hidrológico de forma indirecta por infiltración o por vertido a cauces. Un buen ejemplo de este último uso es el que se le da al agua regenerada procedente de la mayor depuradora de la región (Murcia Este con 38,39 $\mathrm{hm}^{3}$ ), situada en la capital de la provincia, cuyo efluente se vierte en su totalidad al río Segura.

En la Comunidad Valenciana, en 2014, de $\operatorname{los} 419,73 \mathrm{hm}^{3}$ de aguas depuradas, se reutiliza el $62 \%$, aunque tan sólo el 34,7\% se reutiliza de forma directa. De estos recursos reutilizados, el 91,8\% se destinan para usos agrícolas y en segundo lugar, el 6,7\% para usos urbanos. En relación con la reutilización indirecta (vertido a cauces y humedales costeros, e infiltración en acuíferos) $(118,42$ $\mathrm{hm}^{3}$ ) representa el $28,2 \%$ del total depurado. Por provincias, Alicante es la región que más agua reutiliza con el 46,2\%, en segundo lugar Valencia (el 34,8\%) y Castellón con tan sólo el 7,9\%. En este sentido, en la Comunidad Valenciana, cabe poner de manifiesto que se está perdiendo la oportunidad de aprovechar un recurso fácilmente utilizable para algunos usos que puedan demandar este 
tipo de fuente no convencional. Además, ha de subrayarse que el coste medio de producción de este recurso, es de $0,34 € / \mathrm{m}^{3}$, cinco veces más barato que el agua potable. Por lo tanto, se está dejando de aprovechar una fuente alternativa de extraordinario valor desde un punto de vista ambiental y económico, más si cabe si se tiene en cuenta la coyuntura económica actual que puede beneficiar en la reducción de costes con la utilización de este recurso, tanto para agricultores, ayuntamientos, etc. Una de las fórmulas que podría favorecer un mayor nivel de aprovechamiento, particularmente en usos agrícolas, sería la apuesta en territorio valenciano por el modelo de armonización de usos implantado en la Marina Baja, favoreciendo acuerdos entre regantes y abastecimientos para el intercambio de agua regenerada para riego por «agua blanca» para uso urbanoturístico. No obstante, ello exigirá elevar la calidad del recurso regenerado, con líneas de tratamiento terciario avanzado, con ultrafiltración y desalinización, como las implantadas en las EDAR de Benidorm y Rincón de León (Alicante) aunque ello exigirá un mayor nivel de compromiso económico por parte de los usos urbano-turísticos, para hacer frente al mayor coste de producción del agua regenerada, que en estas plantas de última generación supera los $0,40 € / \mathrm{m}^{3}$.

\section{BiBLIOGRAFÍA}

AEMET (2015): Proyecciones Climáticas para el siglo XXI en España. http://www. aemet.es/es/serviciosclimaticos/cambio_climat [Consultado: Junio 2015].

Angelakis, A.; Marecos Do Monte, MHF.; Bontoux, L. y Asano, T. (1999): «The status of wastewaterreuse practice in the Mediterranean basin». Water Res n. ${ }^{\circ} 33(10)$, pp. 2.201-2.217.

AQCUAREC: Programa de investigación para el uso y conservación del agua y sus recursos. Disponible en: http://www.iiap.org.pe/Programas/aquarec.htm

AsANO, T. (1997): «La recuperación de las aguas residuales municipales como nuevo recurso hídrico. En Jornadas Internacionales: Agua Horizonte 2005.

CNA (2002a): Programa Nacional de Regulación del Reuso del Agua 2002. Subdirección General Técnica. Comisión Nacional del Agua. http://www.cna.gob.mx

Enviroment Policy Agency (1992): Disponible en: http://www3.epa.gov/

Epsar (2014): Memoria de Gestión 2014. Entidad Pública de Saneamiento de Aguas Residuales de la Comunidad Valenciana, (Documento Policopiado), $107 \mathrm{p}$.

EsAMUR (2012): Gestión de las aguas residuales urbanas en la Región de Murcia 20022012. Entidad de Saneamiento y depuración de la Región de Murcia

ESAMUR (2014). Disponible en: http://www.esamur.com/

EsPon-Climate (2013): Climate Change and Territorial Effects on Regions and Local Economies in Europe. Disponible en: http://www.espon.eu/main/Menu_Projects/ Menu_AppliedResearch/climate.html

Gil Olcina, A. y Rico Amorós, A.M. (2015): Consorcio de Aguas de la Marina Baja. Gestión convenida, integral y sostenible del agua. Consorcio de Aguas de la Marina Baja. 327 p. 
Gil Olcina, A.; Hernández Hernández, M.; Morote Seguido, A.F.; Rico Amorós, A.M.; Saurí Pujol, D.; March Corbella, H. (2015): Tendencias del consumo de agua potable en la ciudad de Alicante y Área Metropolitana de Barcelona 2007-2013. Hidraqua, Gestión Integral de Aguas de Levante S.A. y Universidad de Alicante, $164 \mathrm{p}$.

Hernández Hernández, M. (2013): «Análisis de los procesos de transformación territorial en la provincia de Alicante (1985-2011) y su incidencia en el recurso hídrico a través del estudio bibliográfico». Documents d'Anàlisi Geogràfica, vol. 59/1, pp. 105-136.

IAGUA (2007): Disponible en: http://www.iagua.es/2007/10/espana-triplicara-sucapacidad-de-reutilizar-aguas-depuradas-antes-de-2015

InSTITUTO NACIONAL DE EsTADÍsTiCA (1998). Disponible en: http://www.ine.es/

Instituto Nacional de Estadística (2012). Agua. Disponible en: http://www.ine.es/

Intergovernmental Panel on Climate Change (2014): Climate Change 2013 and Climate Change 2014 (3 vols.) Disponible en : http://www.ipcc.ch/

Kamizoulis, G., Bahri, A., Brissaud, F. y Angelakis, A. (2003): "Wastewater recycling and reuse practices in Mediterranean region: Recommended Guidelines», Water International, pp. 841-854.

MARCH, H.; DOMÈNECH, L., y SAURí, D. (2013): «Water conservation campaigns and citizen perceptions: the drought of 2007-2008 in the Metropolitan Area of Barcelona». Natural Hazards, n. ${ }^{\circ} 65$, pp. 1.951-1.966.

Martínez Ciscar, J.S. (1995): «El Plan Nacional de Saneamiento y Depuración, indispensable para el desarrollo sostenible». Ciudad y Territorio. Estudios Territoriales, III, n. ${ }^{\circ} 105$, pp.497-502.

Ministerio de Medio Ambiente (2007): Disponible en: http://www.magrama.gob.es/ es/

Ministerio de Medio Ambiente, Rural y Marino (2010): Disponible en: http://www. magrama.gob.es/es/

Ministerio de Agricultura, Alimentación y Medio Ambiente (2012): Plan Nacional de Calidad de las Aguas 2007-2015. Disponible en: http://www.magrama.gob.es/ es/

Morales Gil, A. (2001): Agua y Territorio en la Región de Murcia. Fundación Centro de Estudios Históricos e Investigaciones Locales. Murcia, 270 pp.

Morales Gil, A. y Vera Rebollo, J. F. (1989): La Mancomunidad de los Canales del Taibilla. Instituto Universitario de Geografía de la Universidad de Alicante y Academia Alfonso X El Sabio. Murcia, 132 pp.

Morales Gil, A.; Olcina Cantos, J. y Rico Amoros, A.M. (2000): «Diferentes percepciones de la sequía en España: adaptación, catastrofismo e intentos de corrección». Investigaciones Geográficas, n. ${ }^{2} 23$, pp. 5-46.

Morales Gil, A.; Rico Amorós, A.M. y Hernández Hernández, M. (2005): «El trasvase Tajo-Segura». Observatorio medioambiental, (8), 073-110.

Olcina Cantos, J. (2002): «Planificación hidrológica y recursos de agua no convencionales en España». En: Insuficiencias Hídricas y Plan Hidrológico Nacional. 
Instituto Universitario de Geografía, Universidad de Alicante, Caja de Ahorros del Mediterráneo, pp. 69-130.

Olcina Cantos, J. y Moltó Mantero, E. (2010): «Recursos de agua no convencionales en España: estado de la cuestión, 2010». Investigaciones Geográficas, n. ${ }^{\circ} 51$, pp. 131-163.

Olcina CAntos, J. y Rico Amorós, A. (1999): «Recursos de agua «no convencionales» en España. Depuración y desalación». En Los usos del agua en España. Eds: Gil Olcina, A. y Morales Gil, A. Instituto Universitario de Geografía y Caja de Ahorros del Mediterráneo, Alicante, pp. 203-252.

PÉrez, A.; GiL, E. y Gómez, J.M. (2014): «Las aguas residuales regeneradas como recurso para los regadíos de la Demarcación Hidrográfica del Segura (España)». Boletín de la Asociación de Geógrafos Españoles, 64, 151-175.

Pérez, S.; Köck, M.; Lei Tong; Ginebreda, A.; LóPez-Serna, R.; Postigo, C.; Brix, R.; LóPez de Alda, M.; Petrovic, M.; Wang, Y. y Barceló, D. (2011): "Wastewater Reuse in the Mediterranean Area of Catalonia, Spain: Case Study of Reuse of Tertiary Effluent from a Wastewater Treatment Plant at el Prat de Llobregat (Barcelona)», en D. Barceló and M. Petrovic (eds.) en Waste Water Treatment and Reuse in the Mediterranean Region, Hdb Env Chem.

Rico Amorós, A.M. (2010): «Plan Hidrológico Nacional y Programa A.G.U.A.: Repercusión en las regiones de Murcia y Valencia». Investigaciones Geográficas, n. ${ }^{\circ} 51$, pp. $235-267$.

Rico Amorós, A.M. (1996): «Depuración y reutilización de aguas residuales en el litoral alicantino». Papeles de Geografía, 23-24, 245-261.

Rico Amorós, A. M., Olcina Cantos, J. Paños Callado, V. y Baños Castiñeira, C. (1998): Depuración, desalación y reutilización de aguas en España, Edit. OikosTau, Vilasar de Mar, 255 p.

RwL Water (05/04/2013): «¿En dónde se practica la mayor reutilización de agua?». Disponible en: http://www.rwlwater.com/en-donde-se-practica-la-mayorreutilizacion-de-agua/?lang=es

UsGs (1995): Estimated Use of Water in the United States in 1995. U.S. Geological Survey, Disponible en http://water.usgs.gov/watuse/pdf1995/html/

SEDLAK, D. (2014): Water 4.0. The past, present and future of the World's most vital resource. New Haven, Conn: Yale University Press. 